\title{
Evacuation planning in the Auckland Volcanic Field, New Zealand: a spatio-temporal approach for emergency management and transportation network decisions
}

\author{
Erik Tomsen ${ }^{1,4}$, Jan M Lindsay ${ }^{1 *}$, Mark Gahegan², Thomas M Wilson ${ }^{3}$ and Daniel M Blake ${ }^{3}$
}

\begin{abstract}
Auckland is the largest city in New Zealand (pop. 1.5 million) and is situated atop an active monogenetic volcanic field. When volcanic activity next occurs, the most effective means of protecting the people who reside and work in the region will be to evacuate the danger zone prior to the eruption. This study investigates the evacuation demand throughout the Auckland Volcanic Field and the capacity of the transportation network to fulfil such a demand. Diurnal movements of the population are assessed and, due to the seemingly random pattern of eruptions in the past, a non-specific approach is adopted to determine spatial vulnerabilities at a micro-scale (neighbourhoods). We achieve this through the calculation of population-, household- and car-to-exit capacity ratios. Following an analysis of transportation hub functionality and the susceptibility of motorway bridges to a new eruption, modelling using dynamic route and traffic assignment was undertaken to determine various evacuation attributes at a macro-scale and forecast total network clearance times. Evacuation demand was found to be highly correlated to diurnal population movements and neighbourhood boundary types, a trend that was also evident in the evacuation capacity ratio results. Elevated population to evacuation capacity ratios occur during the day in and around the central city, and at night in many of the outlying suburbs. Low-mobility populations generally have better than average access to public transportation. Macro-scale vulnerability was far more contingent upon the destination of evacuees, with favourable results for evacuation within the region as opposed to outside the region. Clearance times for intra-regional evacuation ranged from one to nine hours, whereas those for inter-regional evacuation were found to be so high, that the results were unrealistic. Therefore, we conclude that, from a mobility standpoint, there is considerable merit to intra-regional evacuation.
\end{abstract}

Keywords: Emergency management; Geospatial analysis; Transportation modelling; Vulnerability; Hazard; Risk

\section{Introduction}

Evacuations are, and most likely will continue to be, the most common and efficient emergency management strategy when a hazardous event threatens and puts at risk the safety of those within the area (Moriarty et al. 2007). Evacuations are also becoming increasingly frequent worldwide as humans continue to develop in hazardous areas and improved technology in many countries allows for prior warnings and the movement

\footnotetext{
* Correspondence: j.lindsay@auckland.ac.nz

'School of Environment, The University of Auckland, Private Bag 92019, Auckland, New Zealand

Full list of author information is available at the end of the article
}

of people before a disaster strikes (Sparks 2003, Woo and Grossi 2009). However, evacuations can produce long-term negative effects such as psychological trauma, and disruption of community cohesion and employment and economic continuity (e.g. Mileti et al. 1991, Lindell and Perry 1992, Cola 1996, Tobin and Whiteford 2002, Perry and Lindell 2003). Poorly managed evacuations tend to lead to a strong resentment of government which, in turn, decreases the ability of emergency management organisations to act effectively in the future (MCDEM 2008). Therefore, effective planning of an evacuation is essential. 


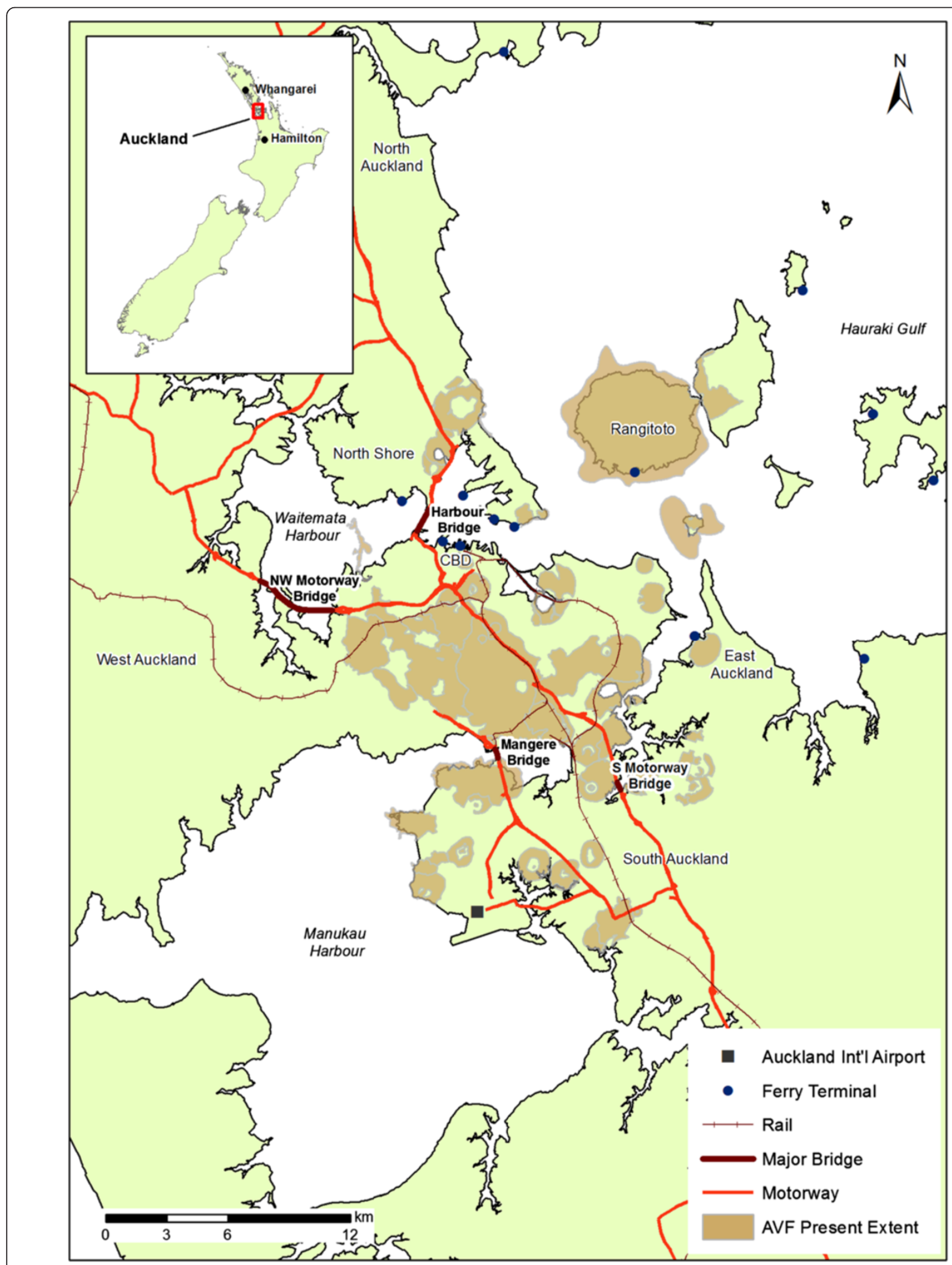

Figure 1 Map of Auckland (inset shows the location of Auckland, Hamilton and Whangarei within New Zealand), showing volcanic deposits of the Auckland Volcanic Field (representing present extent), and key infrastructure elements. 
Volcanic eruptions are capable of producing a spectrum of hazards which are harmful to humans. These hazards range from highly destructive phenomena such as pyroclastic density currents, debris avalanches, lava flows and lahars that typically destroy everything in their path, to less destructive yet highly disruptive phenomena such as ash fall, volcanic tremor and gas release. As many volcanoes and volcanic regions around the world are already heavily populated, the most effective means of risk reduction will be to identify the most hazardous areas and evacuate the population from the danger zone prior to an eruption (Marzocchi and Woo 2007, Lindsay et al. 2011, Sandri et al. 2012).

The city of Auckland, New Zealand, with a population of $\sim 1.5$ million as of December 2012, is built within the $360 \mathrm{~km}^{2}$ potentially active basaltic Auckland Volcanic Field (AVF) (Figure 1), with the last eruption occurring just 550 years ago (Needham et al. 2011). Auckland's geography poses significant constraints for evacuation planning. The city is located on an isthmus bounded by the Waitemata Harbour to the northeast and Manukau Harbour to the southwest. As a result, all land-based transport into and out of the city is constricted through narrow stretches of land serviced by four motorway bridges which form critical links in Auckland's transportation network (Figure 1). To date, there has been no major modelling-based study conducted on the mass evacuation capacity of Auckland. Previous evacuation planning has been mainly strategic and lacking in geospatial analysis and physical evacuation procedures that can be used operationally (Auckland CDEM Group 2008a, Auckland CDEM Group 2008b, Tomsen 2010).

In this study we adopt a novel, non-specific approach (Shulman 2008) in considering the spatial and temporal distribution of population and transport networks across Auckland and how they affect mass evacuation planning. Spatial network analysis is used to determine the geographic functionality of major transport origin and destination points and we determine the relative vulnerabilities of the key motorway bridges to new AVF eruptions. We then assess micro-evacuation vulnerability by combining spatial network analysis with population evacuation demand to calculate evacuation capacity ratios for individuals, households and vehicles. Finally, we employ modelling using dynamic route and traffic assignment to measure evacuation attributes at a macroscale and forecast total network clearance times. This quantitative study thus serves to fill the informational void and provides emergency management officials with a more holistic understanding of the local variations in susceptibility to mass evacuations, particularly those related to volcanic activity in the AVF.

\section{Evacuation planning}

There is a broad body of literature on effective evacuation planning. Many studies have attempted to classify evacuations into various types (e.g. Baker 1991, Ketteridge et al. 1996, Wolshon et al. 2001, Marrero et al. 2010) and others have focussed on emergency response activities (e.g. Cova 1999, Cutter 2003, Marzocchi and Woo 2007, Moriarty et al. 2007, Shaluf 2008). The core components to this evacuation planning can be summarised as: 1) conditions under which an evacuation may be necessary; 2) 'at risk' people/communities who may require evacuation; 3 ) evacuation routes and destinations; and 4) the resources and time required to evacuate 'at risk' people/communities (MCDEM, 2008).

\section{Identifying when an evacuation is necessary}

Evacuation can be classified as an "organised, phased, and supervised withdrawal, dispersal, or removal of civilians from dangerous or potentially dangerous areas, and includes their reception and care in safe areas" (U.S. Department of Transportation 2006, p.2-1). Evacuation becomes necessary when the benefits of leaving significantly outweigh the risk of other options, such as 'sheltering-in-place'. In a volcanic context, evacuation is a response strategy - an effort to preserve human life (Marzocchi and Woo 2007, Auckland CDEM 2013). In order to assist with evacuations, plans are created in advance, identifying key personnel, areas at risk, and mitigation measures to enact (Moriarty et al. 2007). In New Zealand, the Mass Evacuation Plan (MCDEM 2008) is the key sub-national level plan which aims to detail a range of considerations and actions for the mass evacuation of people from a hazardous environment to a relative place of safety (Auckland CDEM Group 2008b). The Auckland Volcanic Field Contingency Plan is more specific and includes planning arrangements for evacuations resulting from an eruption within the AVF (Auckland CDEM 2013). According to the plan, an evacuation will be called by the Auckland CDEM Group if hazard assessment indicates urban or strategic areas may lie within 5 kilometres of the inferred eruption centre and/ or there is a potential risk to life.

\section{'At risk' people and communities}

There is varied focus in the literature about which group or groups tend to be the most 'at risk'. Low-income populations are studied in detail by some (e.g. Morrow 1999, Chakraborty et al. 2005), while others (e.g. Bascetta 2006, Dosa et al. 2007) focus on the elderly and disabled. The low-mobility population (i.e. those without access to a private vehicle), however, are discussed by many and we examine this group further as they will require public modes of transport (Leonard 1985, Hushon et al. 1989, Wolshon et al. 2001). Ideally, people within an evacuation zone evacuate and people resident outside the zone shelter in place. However, evacuations are typically far more complex, with some choosing to remain 
within a zone, and others outside the evacuation zone voluntarily evacuating (termed shadow evacuation, Baker 1991).

Uncertainty as to who will stay and go (the population evacuation demand) makes it difficult to establish credible time estimates for those evacuating, although this is fundamental for evacuation planning. The population evacuation demand is dependent on numerous variables including external conditions such as weather, location of the hazard source and time, as well as human behavioural characteristics inherent in the population (Wolshon 2006, Tomsen 2010). Research on evacuation response rates for hurricane-based evacuations in the United States found that evacuation rates ranged between 33-97\% during the same hurricane, with an average of $47.5 \%$ (Baker 1991). People in high-risk areas, on average, were found to be more than twice as likely to evacuate when compared to low-risk areas. This was attributed to two factors: people residing in high-risk areas are aware of the hazardousness of their location and/or public officials go to greater lengths to evacuate the residents of these areas (Baker 1991). Less data is available for non-compliance to shelter-in-place orders, a factor that often causes emergency management officials the most difficulty. Two recent surveys regarding such unofficial evacuees reported nearly $60 \%$ of respondents leaving before evacuation orders were given during Hurricanes Lili and Katrina (Lindell et al. 2005, Lindell and Prater 2006).

\section{Evacuation routes and destinations}

Evacuation route choice is a complex decision-making process. Some researchers believe that in emergency situations, evacuees will take any possible egress route (Moriarty et al. 2007). However, others contend that people will take the most familiar routes (predominantly motorways), which often become overloaded while capacity on alternative routes remains unused (Prater et al. 2000, Dow and Cutter 2002). During Hurricane Katrina, drivers were more influenced by familiarity with the route than traffic conditions they experienced en route (Lindell and Prater 2006). As stated in the Mass Evacuation Plan for New Zealand (MCDEM 2008, p.56), "the planning process should decide upon primary and secondary evacuation routes from an anticipated affected area", and "evacuation routes should be designed with due consideration to local area hazard maps to ensure that selected routes are appropriate for anticipated hazards". Any potential bottlenecks in traffic movement should also be identified (MCDEM 2008). Many studies in the U.S. have shown that, despite the enormous demand during hurricane evacuations, many roads carry flows well below the predicted maximums (Wolshon 2008). However, contraflow systems are frequently used for evacuations in the U.S. and plans are often well engineered and publicised (Wolshon 2002). Indeed, although studies on hurricane-based evacuations provide valuable information, many differences in characteristics such as risk perception, familiarity and cultural geography, mean that the results cannot be easily extrapolated to other hazards or locations (Marrero et al. 2010). Transportation modelling can be used to help with specific planning objectives, and allow the testing of various assumptions and alternatives.

During evacuations people tend to favour temporary re-location in second homes, hotel/motel accommodation or with family and friends, rather than seeking public shelter (Quarantelli 1985). However, in a mass evacuation, many of the low mobility population and those without social networks or financial resources will require assistance with accommodation from emergency management authorities. For smaller events, 'all-in-one welfare facilities' may be all that are required to service evacuees. However, when the volume of evacuees is likely to be large, separate evacuation and recovery centres may need to be established (MCDEM 2008).

\section{Evacuation resources and time}

The ability of a community to respond to a disaster and cope with its consequences largely depends on its level of preparedness. However, the impact on an evacuated community is reduced when evacuation is carried out in a well-managed and organised manner. During a mass evacuation, transportation networks are the most critical components of a region's infrastructure network, as they facilitate the mobility of the human population. In developed countries, private vehicles have often been the predominant form of mass evacuation (Quarantelli 1980, Drabek 1986, Lindell and Perry 1992, Tierney et al. 2001, Cole and Blumenthal 2004). This is likely due to their prominence in today's society, the flexibility of route and destination choice they allow, as well as their asset value, which many evacuees seek to retain. A survey conducted in 2008 by the New Zealand Ministry of Civil Defence and Emergency Management with regard to evacuation behaviour in Auckland, confirmed this tendency. Of the 2,050 people in the survey, 91.3\% would choose to leave with their own vehicle if required to evacuate due to an AVF eruption (Horrocks 2008b). Alternative forms of transportation such as trains and buses can also be used for evacuation purposes and are particularly beneficial to the low mobility population who may strongly rely on their provision.

When considering the time and resources required for evacuation, it is important to acknowledge the regular diurnal population shift which occurs in most developed countries when people travel to places of work and learning during the day and return home again at night. 
A national telephone survey conducted by Klepeis et al. (2001) across the U.S. demonstrated that while more than $90 \%$ of people are at home and indoors between the hours of $11 \mathrm{pm}$ and $5 \mathrm{am}$, less than $35 \%$ are there from 10 am to $3 \mathrm{pm}$. We expect similar trends to occur in New Zealand, particularly in city environments, although there is little data for comparison at present. In addition to the standard diurnal shift, other spatiotemporal movement patterns exist in urban areas. On weekends and during school holidays, when many residents leave for recreational activities and travel, the population in the urban area sinks compared to its weekday highs. At other times, such as during major concerts, sporting events and conventions, the urban population may grow substantially. When evacuation time estimates are available, emergency management officials can determine how far in advance evacuation orders should be issued. This allows authorities to balance the competing demands of enduring public safety and unnecessary costs associated with imprecise or unnecessary evacuations, i.e. false alarms. Because running evacuation drills is difficult due to the large areas and populations involved, computer simulations based on various traffic analysis models offer the next best option (Franzese and Liu 2008). Current emergency management planning in Auckland assumes that a major evacuation (such as for an impending volcanic eruption) would require 48 hours for authorities to implement (this includes a pre-evacuation-call planning period). This was illustrated in the lead up to the simulated evacuation during a major 2008 exercise based on an Auckland Volcanic Field eruption, Exercise Ruaumoko, when civil authorities wanted to know when the 48 hour 'time window' before outbreak had been entered (Lindsay et al. 2010).

\section{The Auckland Volcanic Field}

When considering evacuation planning for a volcanic field eruption the following factors related to the hazard must be considered: the likelihood; the number of vents expected; the location(s) of the new vent; the area impacted by volcanic hazards (hazard footprint), which is dependent on the style and size of eruptive activity produced during vent opening; and how much warning will be provided by volcano monitoring systems. The two most important factors are the hazard footprint and the location of the eruption, which together allow determination of the necessary spatial extent of the evacuation zone. This section reviews the past known eruptive history of the AVF with particular focus on these two factors.

The AVF (Figure 1) is a geologically young, generally monogenetic, intraplate volcanic field made up of over 50 small basaltic volcanoes, which has been active for
250,000 years with the last eruption $\sim 550$ years ago (Lindsay et al. 2010, Needham et al. 2011, Shane et al. 2013). Being generally monogenetic in nature, each vent is typically only active for a single eruption sequence and new eruptions usually occur in a different location from those before. To date there have been no spatiotemporal trends identified for vents in the AVF. Recent algorithmic analysis by Bebbington and Cronin (2011) has discounted earlier studies that suggested spatiotemporal clustering in the AVF. Instead the spatial and temporal aspects appear independent; hence the location of the last eruption provides no information about the next location.

Previous AVF eruptions have typically been small in volume $\left(<0.1 \mathrm{~km}^{3}\right.$, Allen and Smith 1994), However the last two eruptions, Rangitoto $\left(2 \mathrm{~km}^{3}\right)$ and $\mathrm{Mt}$. Wellington $\left(0.17 \mathrm{~km}^{3}\right)$ are two of the largest in volume, suggesting a possible change in future eruptive behaviour (Lindsay 2010).

The eruption style during vent opening is typically phreatomagmatic, due to rising magma interacting with groundwater and/or seawater (if a vent occurs in the ocean). Some eruptions cease after this stage, leaving broad maars or explosion craters typically 1-2 kilometres in diameter. Where the eruptions continue beyond this stage, subsequent activity is of magmatic Hawaiian style, which produces scoria cones and lava flows. The explosive phreatomagmatic AVF eruptions have generated volcanic hazards such as base surges, a type of pyroclastic density current (denser-than-air flows which can travel at 200-300 $\mathrm{km} \mathrm{h}^{-1}$ and be $>200{ }^{\circ} \mathrm{C}$; Browne 1958, Belousov et al. 2007), shock-waves and ballistics (material $>64 \mathrm{~mm}$ erupted from the vent) which are highly destructive to areas up to 3 kilometre radius of the vent. Secondary hazards, such as earthquakes, tephra fall and gas release, would also be noticed throughout the entire region. The footprint of these hazards from previous AVF eruptions and those of other analogous volcanoes have been used to calculate evacuation zones for future events. Current contingency and mass evacuation plans call for areas of 3 kilometres ("Primary Evacuation Zone") and 5 kilometres ("Secondary Evacuation Zone") radius from the erupting vents to account for base surges (Beca Carter Hollings and Ferner Ltd. 2002, Auckland CDEM Group 2008b, Auckland CDEM 2013).

Finally, It is likely that civil authorities and area residents will only be provided with at most a few weeks and as little as a few days of warning time prior to an eruption (Beca Carter Hollings and Ferner Ltd. 2002). This is based on the expected fast magma ascent rates (1-10 $\left.\mathrm{cm} \mathrm{s}^{-1}\right)$ that basaltic volcanic fields are known to exhibit (Blake et al. 2006, Sherburn et al. 2007). Early detection of precursory activity is therefore critical. However, the factors contributing to a decision by emergency 
management officials to call a mass evacuation bring significant levels of uncertainty to mass evacuation planning in Auckland. Furthermore, the exact vent area is likely to be unknown until shortly before outbreak (Blake et al. 2006). One attempt to address this uncertainty was presented by Sandri et al. (2012), who developed a cost-benefit analysis model for evacuation planning by weighing the cost of issuing evacuation warnings for geographic areas (represented by lost work potential, warning costs, movement costs etc.) against the benefit of evacuating (represented by the number of lives saved). When the benefits of evacuating a certain area exceed the associated costs, an evacuation is deemed warranted. The point of changeover is the ideal boundary to use as the time to call for evacuation. Sandri et al. (2012) calculated probability threshold values for a range of magnitudes: small effusive, moderate phreatomagmatic and large phreatomagmatic eruptions. Evacuation radii for these three scenarios were established at 3.5, 5 and 8 kilometres respectively. These are somewhat consistent with the primary (3 $\mathrm{km}$ radius) and secondary (5 $\mathrm{km}$ radius) evacuation zones in the AVF contingency plan, but crucially suggest an additional larger radius of $8 \mathrm{~km}$ should be considered in evacuation demand analysis. The evacuation area was also found to change in size with time in the lead-in period, due to a reduction in the uncertainty in the vent location and increase in the probability of an eruption. Thus, there is a trade-off between these two factors (area and time) that dictates which cells must be evacuated, and when (Sandri et al. 2012). Given the uncertainty in vent location (and the subsequent need to wait until close to outbreak to define the evacuation area) it is likely that the evacuation will need to be carried out quickly, i.e. within the 48-hour evacuation time required by civil authorities.

\section{Data sources}

Two primary types of data are used in this study: population data and infrastructure data. Population data from Statistics New Zealand, which provides data in its Census of Population and Dwellings, was sourced from the results of the 2006 census. Census areas are arranged hierarchically with regions representing the most extensive geographical areas, and meshblocks representing the smallest areas. The more detailed meshblock scale is used for determining evacuation demand in this research. We also use neighbourhood areas; defined here as areas bounded by major and arterial roads, motorways, or saltwater inlets. Census data utilised in the research includes night-time population, average household sizes, ages, income levels, vehicle availability per household, and business demography. Data regarding school attendance was obtained from the Ministry of Education. The majority of infrastructure data employed was provided by the former Auckland Regional Council and were current as of October 2009. This included geospatial road data files, which contained comprehensive attributes for the Auckland region such as road hierarchy, designated speed limits and directionality. In order to facilitate macro-evacuation studies covering areas outside Auckland, major and arterial road and motorway data for Northland and Waikato, produced by NZ Open GPS Maps (2009), was added to the database. Since our study a new Census has been carried out in New Zealand, and we note that it would be worthwhile repeating this study with post-2009 infrastructure data together with the new (2013) Census data once it becomes available.

\section{Methods}

\section{Constraining the study area}

Various size estimates have been employed to represent the size of the AVF. For this study we adopt the same bounding limits used by Lindsay et al. (2010), reflecting the continuity of the underlying geology and recognising the possibility of eruptions taking place outside the current extent of the AVF. However, we employ an ellipse rather than a rectangular area since established volcanic fields are more often ovular in shape (Spörli and Eastwood 1997). The resulting ellipsoid (Figure 2) represents the large conservative 'future geologic extent' of the AVF and is used as the theoretical boundary of the field in this study. Subsequent to our study, further work by Le Corvec et al. (2013a,b) has provided new insights into a smaller quantitative boundary for the AVF. Were such a smaller, less-conservative ellipsoid representing the current extent of the AVF used, all of our calculated probabilities would be much larger, as the total area (much of which is water) is reduced. Also, the chance of zero evacuation demand would likely be minimal, particularly if evacuations resulting from tsunami generated by offshore eruptions were incorporated into the study.

\section{Population evacuation demand}

Traditional census data in New Zealand reports the population according to their night-time residence but does not cover daytime population figures. Business demographics data from Statistics New Zealand (2008) and school enrolment data for 2009 provided by the Ministry of Education were thus used to estimate Auckland's daytime population. Using employing units with a Goods and Services Tax turnover of $\$ 30,000$ or more, there were 593,276 people employed in Auckland and 601,638 people employed from Auckland, suggesting that roughly $1.4 \%$ of Aucklanders leave the region for work. The number of students enrolled in Auckland schools was 244,449. As the Ministry of Education do not code their data to show where students reside, a proxy value 


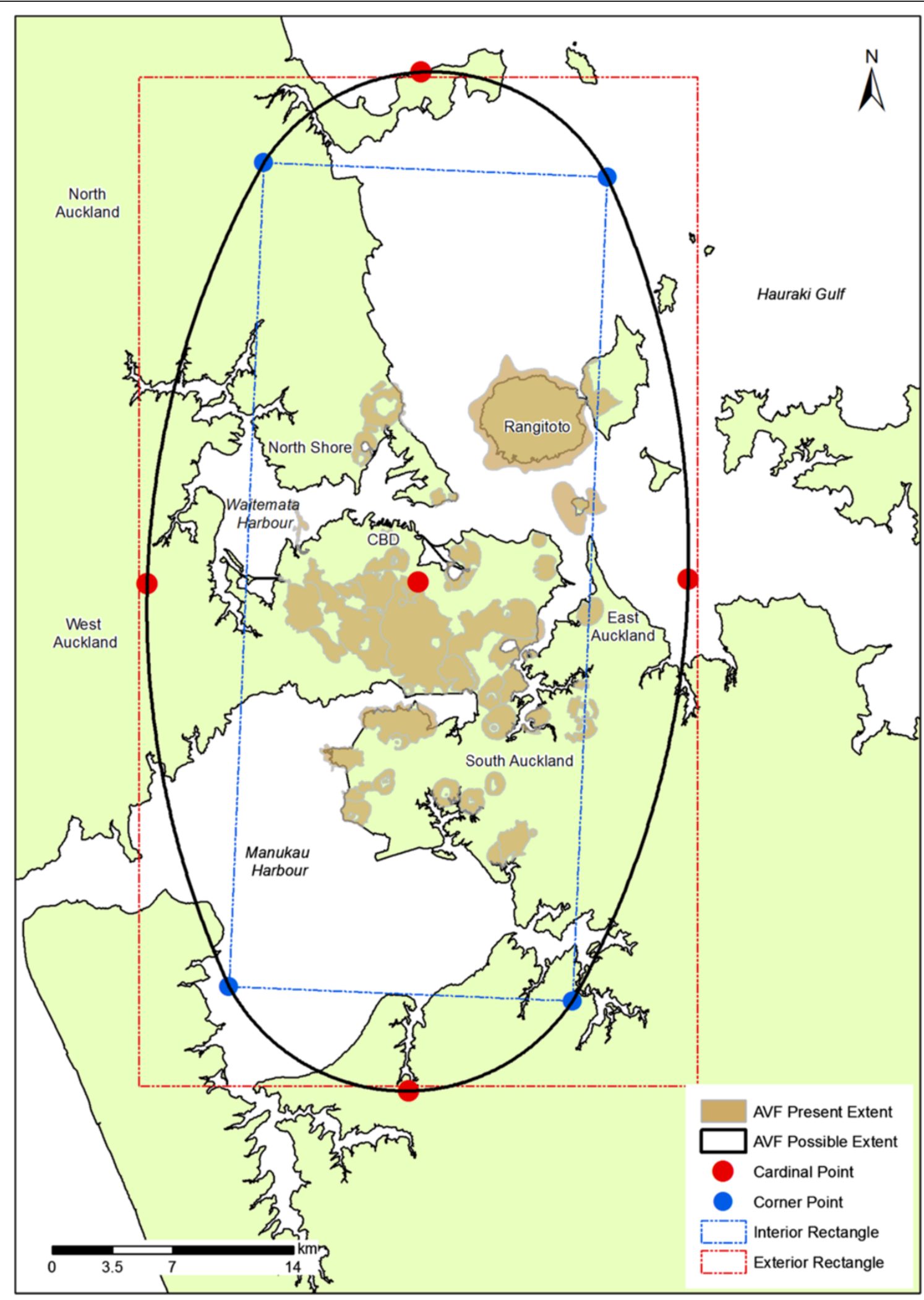

Figure 2 Geometry of the Auckland Volcanic Field. The ellipsoid represents the possible future geologic extent of the AVF and is used in this study as the presumed theoretical boundary of the field. 
based on age cohorts from the census data was obtained (sum of age 5-9, 10-14 and 15-19 cohorts). However, as not all people in this range attend school, the proxy value $(281,460)$ overestimates the enrolment generation by $15 \%$. Equation 1 , which was used to generate daytime population, used the night-time population as a baseline measure and added the inflows of workers and students, then subtracted their outflows:

$$
\begin{aligned}
\text { Day pop. }= & \text { Census night pop. }+ \text { workers in } \\
& + \text { school in-workers out }- \text { school out }
\end{aligned}
$$

Using the night-time and daytime statistics together allows the magnitude of diurnal movement of Auckland's populations to be calculated. However, although diurnal trends in population are thoroughly assessed in this study, these are largely based on scenarios for a typical weekday. Further work to obtain detailed estimates of population distribution over space and time would greatly assist evacuation planning in Auckland.

To calculate population evacuation demand, we assumed that all evacuees in the danger areas would evacuate, and that there is no shadow evacuation outside of those areas. While these assumptions are simplistic and unlikely to represent the true human dynamics of a mass evacuation, they allow for the creation of baseline values. We also assumed an equal probability distribution of a new vent forming anywhere in the AVF and calculated population evacuation demand (at 100-metre resolution) during day and night for every point in the AVF. This was accomplished first by determining the population density of each census meshblock and transforming the densities into aerial-based population values in ArcGIS (2009). Then, the AVF extent ellipsoid was buffered by the evacuation radius values. This was done to reflect the reality that eruptions occurring on the edge of the AVF will impact those within the evacuation radius even if they are outside the AVF boundary. In the final step of the process, the population evacuation demand was calculated for each $100 \mathrm{~m}^{2}$ cell by summing the values of the individual cells within designated neighbourhood distances. The three evacuation radii proposed by Sandri et al. (2012), 3.5, 5 and 8 kilometres, were used as the neighbourhood distances in successive calculations, thus producing three models. Each model was clipped to match the extent of the AVF study area and contour lines were created at intervals of 50,000 people to enable improved visualisation of the data. The cells were also reclassified into 50,000 unit intervals, allowing the results to be displayed numerically as 11 classes. For ease of comparison, we focus our results on the 5 kilometre evacuation radii, which is also the larger of the 'most probable' evacuation radii used in the current AVF contingency plan.
In addition to total number of evacuees, the lowmobility population evacuation demand is also of concern for public authorities, particularly as they may rely on public transportation. Both census and school enrolment data were used to determine the spatial and numeric extent of the population without a vehicle for each meshblock using Equations 2 and 3 for night and day respectively.

$$
\begin{aligned}
& \text { Low mobility pop.(night) }= \\
& \quad \text { no motor vehicle households } \\
& \times \text { average household size (2) } \\
& \begin{aligned}
\text { Low mobility pop. }(\text { day })= & (\text { \#motor vehicle households } \\
& \times \text { av.household size }) \\
& + \text { school enrolment }
\end{aligned}
\end{aligned}
$$

It was assumed that no school children drive to school. Therefore, all school children are considered lowmobility during the day, but not at night when they return home to their families. Population evacuation demand figures for the low-mobility population were calculated using a similar technique as for the general population, the major alteration being that low-mobility meshblock statistics, rather than total meshblock statistics, were adopted as the inputs. The statistical results were reclassified into 12 classes at 10,000 unit intervals.

\section{Network analysis}

Two types of network analysis were conducted in this study: Spatial analysis to determine the geographic functionality of different transport hubs and evacuation destinations; and vulnerability analysis for the four major motorway bridges which are integral to Auckland's transportation network. ArcGIS (2009) was employed, with constraining values such as movement restrictions and distances adopted to calculate populations that reside within easy reach of different transportation assets. Such assets included public transport stops (bus stations, ferry terminals and train stations), boat ramps, marinas and welfare facilities. It should be noted that public transportation in Auckland is more limited at certain times such as at night and at weekends, and that the functionality of such transport depends on the reliability of its workers and their ability and willingness to travel to work, no matter what the timing.

All roads and footpaths in Auckland were used to create the network dataset and the daytime and night-time populations for meshblocks within transport service areas were summed. We chose 30 minutes as the maximum time that evacuees would be willing to walk to a departure point and, based on a consistent walking rate of $5 \mathrm{~km} \mathrm{~h}^{-1}$, a time interval representing accessibility was set correspondingly. As most boat owners access 
boat ramps using motor vehicles, we adopted an accessibility time interval of 15 minutes, based on average rush hour speeds for different road types (Auckland Regional Council 2009b) for this asset type.

The four primary motorway bridges that form essential links in Auckland's transportation network are the Auckland Harbour Bridge and Northwest Motorway Bridge at the north end of the isthmus, and the Southern Motorway Bridge and Mangere Bridge at the south end (Figure 1). For the purpose of this study, the vulnerability of these bridges was based on the likelihood of the structures lying within each of the designated evacuation radii. Geospatial buffers were created for each bridge to match the extent of the three evacuation radii and these were subsequently clipped to the extent of the AVF. The resulting areas were then divided by the total area of the AVF. This provided the probability that any bridge would intersect the evacuation zone and thus would likely be damaged or made unusable by the eruption. The directional vulnerability (i.e. that either bridge in one direction would be impacted) and combined vulnerability of any of the four bridges being impacted was also assessed. We achieved this by merging and intersecting the existing bridge-evacuation radii areas with one another in ArcGIS (2009) and dividing the new areas by the total area of the AVF.

\section{Evacuation vulnerability}

Evacuation vulnerability was analysed at both the microand macro-scale. In order to assess evacuation difficulty at the micro-scale, we employed a method using population to exit capacity (P/EC) ratios, first pioneered by Cova and Church (1997). Neighbourhoods, which are commonly used for transportation modelling, were used as a key unit of analysis for this study. This was deemed appropriate, as evacuation zones need to be easily differentiated by the public and neighbourhood boundaries (i. e. major and arterial roads, motorways and saltwater inlets) are easily distinguishable by eye. Although there is no mention of boundary delineation in the current mass evacuation plan for Auckland, clear geographic and functional features were used to determine evacuation zones during Exercise Ruaumoko (see Lindsay et al. 2010). Therefore we used saltwater inlets, motorways, and major and arterial roads to define the neighbourhoods and thus evacuation zone boundaries in this study. This ensures that the majority of traffic will flow towards the periphery of the neighbourhood from the onset of evacuation, rather than to a point within the zone, and then outwards. After determining the neighbourhood zones, the points where each road intersected the neighbourhood boundary were designated as exits. Exits were coded according to the neighbourhood they serviced and their capacity, and half of all one-way streets were removed, as the direction of flow for these was indiscernible. The total exit capacity for each neighbourhood was generated and daytime and night-time populations were calculated based on the neighbourhood areas. Dividing the populations by the total exit capacities thus produced the P/EC ratios.

To statistically test correlations between $\mathrm{P} / \mathrm{EC}$ ratios and neighbourhoods with different constricting boundary types (i.e. motorways and water), we employed a two-tailed t-test with a $95 \%$ confidence interval. The null hypothesis stated that there was statistically no difference between the mean of the first data set $\left(\mu_{1}\right)$ and the second data set $\left(\mu_{2}\right)$. The alternative hypothesis claimed that the difference is statistically significant. Four t-tests were performed. The first three assessed each of the two constricting boundary types individually and in combination against the neighbourhoods with neither boundary type. The final assessment compared neighbourhoods with neither boundary type against all data values in aggregate.

As most evacuees in developed countries prefer to evacuate by private vehicle, we assumed that each household leaves in one vehicle, and, following the same procedure used to calculate $\mathrm{P} / \mathrm{EC}$ ratios, household to exit capacity (HH/EC) ratios were calculated. Sensitivity analysis on this assumption was also conducted by assuming that all available vehicles per household are used during evacuation. This was achieved first by using Equation 4, followed by the same method that was used to calculate $\mathrm{P} / \mathrm{EC}$ ratios, thus determining Car/EC ratios.

$$
\begin{aligned}
\text { Cars }= & n_{H H}(\text { one car }) \times 1+n_{H H}(\text { two cars }) \times 2 \\
& +n_{H H}(\text { three or more cars }) \times 3
\end{aligned}
$$

where $n_{H H}$ represents the number of households in each census meshblock.

Equation 4 slightly underestimates the number of cars per meshblock, because it is based on the assumption that no household has more than three cars, which some likely do, though data that would resolve this is unavailable at present.

TransCAD models were built to assess the feasibility of overland movements along the regional roadway network in Auckland and to test various independent variables on a macro-scale to determine the degree to which they impact the network clearance time (TransCAD, developed by Caliper Corporation, is a GIS with highly specialised transportation modelling capabilities). Such models dissect the transportation network as a set of links (roads) and nodes (intersections or endpoints). Centroids are a special set of nodes representing the geographic centre of a Traffic Analysis Zone (TAZ). Centroids begin and end every modelled trip and therefore represent both origin (neighbourhood) and 
destination (welfare facility) locations. They are connected by the Auckland road network, which is generalised to improve processing. A generalised road network also has the advantage of more realistically modelling evacuation flows because the public's knowledge of the road network will be imperfect and they are most likely to remain on more familiar routes such as major roads and motorways (Tomsen 2010).

Designated Auckland Civil Defence and Emergency Management welfare facilities were chosen as the destination locations for intra-regional evacuation studies on the macro-scale. This is because, in an ideal situation, all evacuees would go to such a facility to register with emergency management officials before heading to their final destination. For inter-regional analysis, two major welfare facilities outside the Auckland region, one in Hamilton (south) and the other in Whangarei (north) were chosen as the destination locations (Figure 1). For the purpose of this study, the road network outside of the Auckland region was generalised in two ways: motorways only, and motorways in combination with major arterial roads. However, within the Auckland region, all major and arterial roads were utilised, forming the intricate lattice of TAZ boundaries. In macro-evacuation models, TAZs do not contain intra-zonal roads; therefore, secondary roads in Auckland were removed by definition. Vehicle capacity values were assigned to each road type in the models. As capacity values were not available for Auckland, estimates provided in the Brisbane Strategic Transport Model (Brisbane City Council 2007) were adopted. These values range from 1,100 vehicles per lane per hour for arterial roads to 2,100 vehicles per lane per hour for 4-lane motorways. The number of centroid connectors determines the number of neighbourhood exits that are utilised. While this has no impact on intra-zonal movement, the effects of congestion begin as soon as the first non-centroid node is reached. To determine the effect of this congestion, the number of centroid connectors was varied as a form of sensitivity analysis. Other forms of sensitivity analysis included modification for time of day, evacuation radii, vent locations, welfare facility locations, shadow evacuations and various levels of road network detail.

TransCAD models were run for AVF vent locations with minimum and maximum population evacuation demand values using the 5 kilometre evacuation radius (determined from results of the micro-vulnerability work). Since there were multiple locations with no evacuation demand, vent locations furthest from the coast in both Waitemata and Manukau Harbours were selected as the minima. The maximum population evacuation demand value was generated from a vent location one kilometre south of Mount Eden. Additionally, the vent used for Exercise Ruaumoko, 0.7 kilometres west of Mangere Bridge in the Manukau Harbour (see Lindsay et al. 2010), was also selected as a scenario.

Outputs from TransCAD models include total flows over the entire network, Volume-Over-Capacity (VOC) ratios and total network clearance times. Flows indicate the total volume of traffic passing over each network link, which in turn provides data on which links are most heavily used and thus the most critical during evacuations. Total flows over the entire network equalled the total number of vehicles involved in the evacuation. Flows alone, though useful in visualising movement, cannot predict congestion, because they do not account for the capacity of the road segments. VOC ratios excel at this and are a common measure of assessing movement difficulty (Cova and Church 1997, Church and Cova 2000, Shulman 2008, Marrero et al. 2010). VOC ratios examine the volume of traffic on each lane of the road divided by the lane's capacity (similar to Car/EC ratios, except VOC ratios are based on links rather than zones). High ratios are indicative of congestion and when the VOC approaches 1, the velocity of traffic approaches 0 . The clearance time (i.e. the time required to evacuate Auckland) was calculated for different inter- and intra-regional evacuation scenarios by linking the network travel times to the original road network.

TransCAD models, like all other evacuation models, rely on the accuracy of the data they employ and the underlying assumptions within the models. While the baseline datasets of population and road infrastructure are accurate, the derivative datasets used to produce origin-to-destination functions are highly dependent on the validity of numerous assumptions. Some assumptions, including evacuation compliance, shadow evacuation and vehicle use rates can be measured indirectly through questionnaires and tested in models with sensitivity analysis; others, such as the destination of evacuees, can only be presumed and aggregated. Further assumptions are built into the model and cannot be altered. For instance, TransCAD models rely on a constant road network and consistent driver interaction. This ignores the possibility of traffic accidents, network alterations due to ongoing damage, and the possibility of panic or "road rage" on the part of drivers. A further limitation with TransCAD is its click-and-run start-up method, which prevents evacuees from being added to the model at successive time intervals. Essentially, the number of evacuees the model begins with is how many it processes to completion. No variation in preparation time is accounted for. Models are also limited to egress population movements, disregarding background traffic. Background traffic is a legitimate concern if little forewarning is provided (Urbanik 2000); yet, when sufficient forewarning is provided (as is expected with an AVF 
eruption), background traffic is unlikely to pose significant issues (Lindell and Prater 2007).

\section{Results}

\section{Population evacuation demand}

The total night-time population of Auckland, based on the raw census data (2006) was 1,264,011. The daytime population based on typical worker and student migration was calculated to be $1,218,638$. Thus, a loss of $3.6 \%$ of the population is noted in the statistics and used as the basis of further analysis for this study. Geographic analysis of diurnal movement in Auckland showed that areas of greatest population gain during the day were business areas, whereas areas of greatest population loss were residential areas. The Central Business District (CBD) had nearly three times the population influx of any of Auckland's other 238 neighbourhoods and thus is likely to be much more difficult to evacuate during the day than night.

The numeric results of the population evacuation demand model outputs are presented in Table 1. Two outputs of this model, utilising the 5 kilometre evacuation radii and the two time variables, are shown in Figure 3. The percentage values reflect the proportion of the cells in the AVF that fall into each category. Because this study employs an equal probability distribution of an eruption occurring at any location in the AVF, the percentage values also represent the likelihood that a future AVF eruption will generate the number of evacuees listed in each class. For instance, using a 5 kilometre evacuation radius, there is a $56.4 \%$ chance that $1-50,000$ evacuees will result from a daytime eruption.

Table 1 Population evacuation demand statistics

\begin{tabular}{|c|c|c|c|c|c|c|}
\hline \multirow{2}{*}{$\begin{array}{l}\text { Evacuation } \\
\text { Demand }\end{array}$} & \multicolumn{3}{|c|}{ Day } & \multicolumn{3}{|c|}{ Night } \\
\hline & $3.5 \mathrm{~km}$ & $5 \mathrm{~km}$ & $8 \mathrm{~km}$ & $3.5 \mathrm{~km}$ & $5 \mathrm{~km}$ & $8 \mathrm{~km}$ \\
\hline 0 & $11.8 \%$ & $3.9 \%$ & $0.0 \%$ & $11.7 \%$ & $3.9 \%$ & $0.0 \%$ \\
\hline $1-50,000$ & $65.5 \%$ & $56.4 \%$ & $37.3 \%$ & $62.3 \%$ & $50.8 \%$ & $32.4 \%$ \\
\hline $50,000-100,000$ & $18.7 \%$ & $18.0 \%$ & $13.0 \%$ & $23.6 \%$ & $20.9 \%$ & $13.7 \%$ \\
\hline $100,000-150,000$ & $2.1 \%$ & $11.2 \%$ & $12.1 \%$ & $2.3 \%$ & $19.5 \%$ & $11.7 \%$ \\
\hline $150,000-200,000$ & $1.2 \%$ & $5.7 \%$ & $10.4 \%$ & $0.0 \%$ & $3.8 \%$ & $13.4 \%$ \\
\hline $200,000-250,000$ & $0.8 \%$ & $2.5 \%$ & $5.9 \%$ & $0.0 \%$ & $1.1 \%$ & $9.7 \%$ \\
\hline $250,000-300,000$ & $0.0 \%$ & $1.7 \%$ & $5.0 \%$ & $0.0 \%$ & $0.0 \%$ & $7.2 \%$ \\
\hline $300,000-350,000$ & $0.0 \%$ & $0.6 \%$ & $4.9 \%$ & $0.0 \%$ & $0.0 \%$ & $5.8 \%$ \\
\hline $350,000-400,000$ & $0.0 \%$ & $0.0 \%$ & $4.3 \%$ & $0.0 \%$ & $0.0 \%$ & $6.0 \%$ \\
\hline $400,000-450,000$ & $0.0 \%$ & $0.0 \%$ & $4.7 \%$ & $0.0 \%$ & $0.0 \%$ & $0.0 \%$ \\
\hline $450,000-500,000$ & $0.0 \%$ & $0.0 \%$ & $2.5 \%$ & $0.0 \%$ & $0.0 \%$ & $0.0 \%$ \\
\hline Average & 27,210 & 55,077 & 137,317 & 27,088 & 55,346 & 134,268 \\
\hline Minimum & 0 & 0 & 6 & 0 & 0 & 6 \\
\hline Maximum & 237,405 & 327,937 & 505,677 & 131,841 & 239,895 & 397,549 \\
\hline
\end{tabular}

Larger evacuation radii were found to substantially increase the average and maximum population evacuation demands and diminish the initial spike in evacuation demands present for smaller radii. During daytime, evacuation demand values are high around the CBD area but become more widely dispersed as the radius increases or during night-time. Correspondingly, the maximum evacuation demand values are substantially smaller for night-time than daytime evacuations (the average maximum daytime value is 357,000 using all three radii, while the average maximum night-time value is 256,000). The results show that there are some locations in the AVF that would generate no evacuation demand, because the vents are located sufficiently far offshore (reflected as zero values in Table 1). Using the 3.5 kilometre radius, there is a $12 \%$ chance that an eruption will generate no evacuees. Using the 5 kilometre radius, this figure is reduced to $4 \%$, and with an 8 kilometre radius to $0 \%$, though the minimum values remain quite low. However, it should be noted that we do not consider evacuation need due to tsunami generated by offshore volcanic eruptions in our study. Such an event may result in increased evacuation demand in coastal areas.

\section{Low-mobility population evacuation demand}

Based on school enrolment figures and households with no vehicles, there are 321,162 people with low-mobility in Auckland during the day and 76,713 people at night. This represents $25.4 \%$ and $6.1 \%$ of Auckland's total population, respectively. These calculations may overestimate the daytime low-mobility population, since lowmobility groups increasingly use social networks to obtain rides with friends or neighbours rather than relying on public transportation (Lindell and Prater 2007). Additionally, an unknown percentage of school children come from low-mobility households and thus would be double-counted during the day, and some parents may pick up children from school during an evacuation. A proportion of older students may also drive to school, although we expect that this is more prevalent in rural communities than urban centres such as Auckland. All of these variables however, are somewhat counterbalanced by an underestimation of the number of households with no access to motor vehicles, which result from the meshblock level census data for car ownership providing no data for some areas (due to small sample sizes being deemed confidential by Statistics New Zealand). Also, other low-mobility groups such as the hospitalised and institutionalised are omitted from the calculations. The former Auckland Regional Council calculated that $7.4 \%$ of Aucklanders have no access to a motor vehicle - a figure comparative to the $6.1 \%$ value used in this study, justified as the council's calculations are based on a regional rather than meshblock scale 


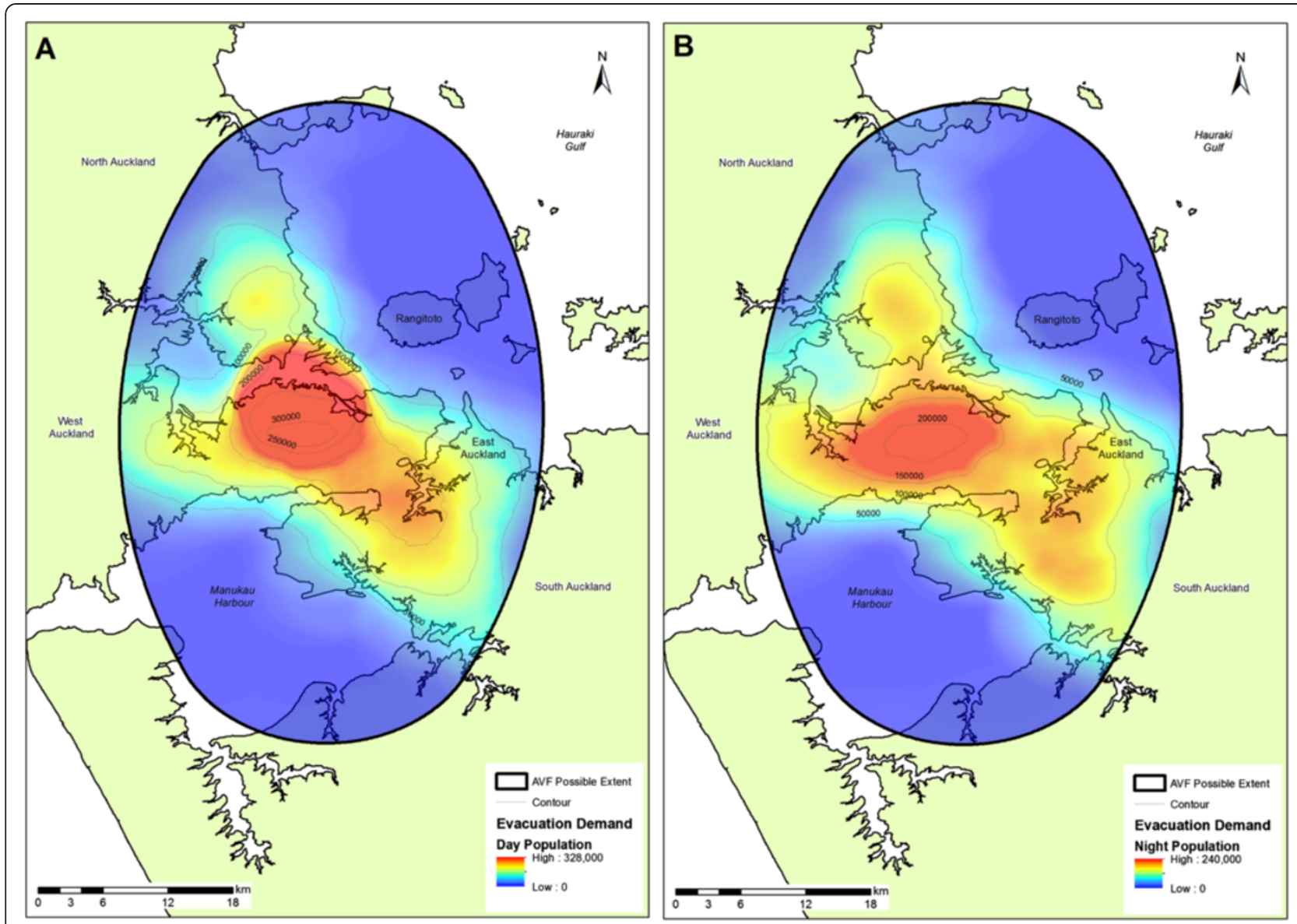

Figure 3 Daytime (A) and night-time (B) population evacuation demand for a 5 kilometre evacuation radius. Note the different scales used for the daytime and night-time evacuation demand colour-ramps.

(Auckland Regional Council 2009a). The statistical results for the low-mobility population evacuation demand are presented in Table 2 and two outputs of the geographic model utilising the 5 kilometre evacuation radii and two time variables, are shown in Figure 4, overlaid atop the ferry and rail station stops.

\section{Network analysis}

Geospatial network analysis showed that the bus network, with a high number of stops and wide geographic distribution, was accessible to the majority of the Auckland population. Based on a standardised walking rate of $5 \mathrm{~km} \mathrm{~h}^{-1}$, over $92 \%$ of Aucklanders can reach a bus stop within a 30 minute walk regardless of the time of day. Other networks such as trains and ferries, were significantly less accessible; The number of Aucklanders who can reach train stations or ferry terminals within a $30 \mathrm{mi}-$ nute walk were $37 \%$ (night-time) to $47 \%$ (daytime) and those who can reach ferry terminals in the same time were $5 \%$ (night-time) to $12 \%$ (daytime). The percentage of people living within a 15-minute drive, based on typical rush hour traffic speeds (Auckland Regional Council
Table 2 Low-mobility population evacuation demand statistics

\begin{tabular}{|c|c|c|c|c|c|c|}
\hline \multirow{2}{*}{$\begin{array}{l}\text { Evacuation } \\
\text { Demand }\end{array}$} & \multicolumn{3}{|c|}{ Day } & \multicolumn{3}{|c|}{ Night } \\
\hline & $3.5 \mathrm{~km}$ & $5 \mathrm{~km}$ & $8 \mathrm{~km}$ & $3.5 \mathrm{~km}$ & $5 \mathrm{~km}$ & $8 \mathrm{~km}$ \\
\hline 0 & $20.6 \%$ & $11.8 \%$ & $4.0 \%$ & $21.0 \%$ & $11.8 \%$ & $4.0 \%$ \\
\hline $1-10,000$ & $47.7 \%$ & $40.2 \%$ & $26.9 \%$ & $78.7 \%$ & $77.7 \%$ & $59.3 \%$ \\
\hline $10,000-20,000$ & $22.5 \%$ & $15.0 \%$ & $10.9 \%$ & $0.4 \%$ & $10.5 \%$ & $22.9 \%$ \\
\hline $20,000-30,000$ & $7.3 \%$ & $14.1 \%$ & $8.6 \%$ & $0.0 \%$ & $0.0 \%$ & $13.5 \%$ \\
\hline $30,000-40,000$ & $1.9 \%$ & $12.7 \%$ & $9.2 \%$ & $0.0 \%$ & $0.0 \%$ & $0.4 \%$ \\
\hline $40,000-50,000$ & $0.0 \%$ & $4.5 \%$ & $10.0 \%$ & $0.0 \%$ & $0.0 \%$ & $0.0 \%$ \\
\hline $50,000-60,000$ & $0.0 \%$ & $1.3 \%$ & $7.1 \%$ & $0.0 \%$ & $0.0 \%$ & $0.0 \%$ \\
\hline $60,000-70,000$ & $0.0 \%$ & $0.5 \%$ & $7.0 \%$ & $0.0 \%$ & $0.0 \%$ & $0.0 \%$ \\
\hline $70,000-80,000$ & $0.0 \%$ & $0.0 \%$ & $5.2 \%$ & $0.0 \%$ & $0.0 \%$ & $0.0 \%$ \\
\hline $80,000-90,000$ & $0.0 \%$ & $0.0 \%$ & $4.0 \%$ & $0.0 \%$ & $0.0 \%$ & $0.0 \%$ \\
\hline $90,000-100,000$ & $0.0 \%$ & $0.0 \%$ & $5.7 \%$ & $0.0 \%$ & $0.0 \%$ & $0.0 \%$ \\
\hline $100,000-110,000$ & $0.0 \%$ & $0.0 \%$ & $1.5 \%$ & $0.0 \%$ & $0.0 \%$ & $0.0 \%$ \\
\hline Average & 6,945 & 13,993 & 34,672 & 1,722 & 3,473 & 8,652 \\
\hline Minimum & 0 & 0 & 0 & 0 & 0 & 0 \\
\hline Maximum & 39,283 & 66,629 & 108,455 & 11,375 & 19,073 & 31,610 \\
\hline
\end{tabular}



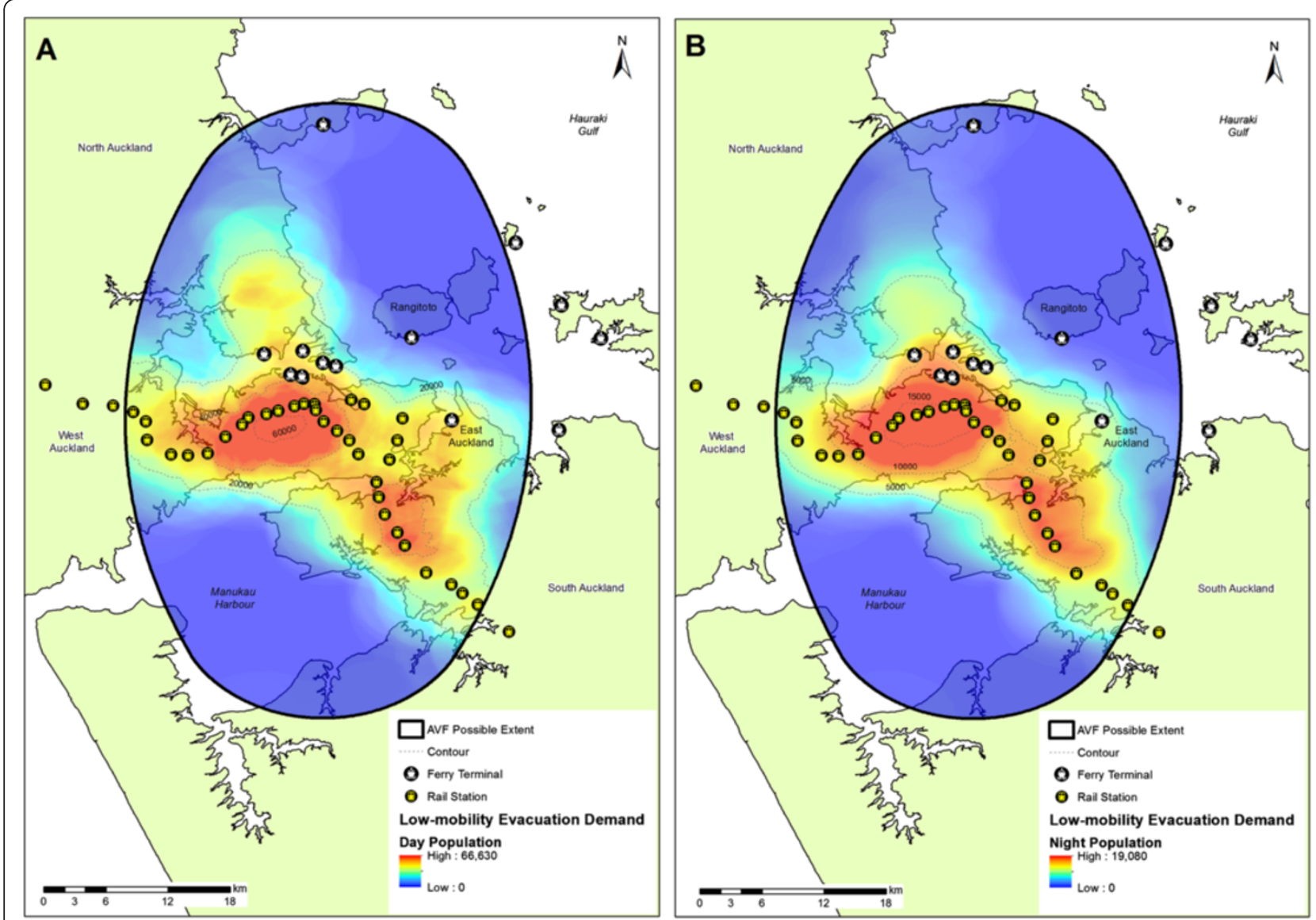

Figure 4 Daytime (A) and night-time (B) low-mobility population evacuation demand for a 5 kilometre evacuation radius. Note the different scales used for the daytime and night-time evacuation demand colour-ramps.

$2009 \mathrm{~b})$, of the nearest marina is relatively low (31-37\%), whereas the percentage within 15 minutes of a boat ramp is high $(90-92 \%)$.

Individual vulnerable bridge probability values for the three evacuation radii range from $3.1 \%$ to $14.7 \%$. Combined bridge vulnerability statistics are listed in Table 3. The maximum probability of either one of the north or south bridges being impacted nearly doubles as the radius is increased. For the 5 kilometre evacuation radius, there is a $1.7 \%$ chance that both north bridges, and a $1.5 \%$ chance that both south bridges, will be impacted but $0 \%$ chance that three bridges will be impacted by the

Table 3 Combined bridge vulnerability statistics

\begin{tabular}{llll}
\hline Bridges & $\mathbf{3 . 5} \mathbf{~ k m}$ & $\mathbf{5} \mathbf{~ k m}$ & $\mathbf{8} \mathbf{~ k m}$ \\
\hline Any & $12.7 \%$ & $21.5 \%$ & $38.7 \%$ \\
Either North & $7.3 \%$ & $11.9 \%$ & $21.8 \%$ \\
Either South & $5.4 \%$ & $9.6 \%$ & $20.6 \%$ \\
Both North & $0.2 \%$ & $1.7 \%$ & $7.7 \%$ \\
Both South & $0.2 \%$ & $1.5 \%$ & $7.3 \%$ \\
NW, Harbour \& Mangere & $0.0 \%$ & $0.0 \%$ & $1.7 \%$ \\
\hline
\end{tabular}

eruption (Figure 5). In the event of an 8 kilometre evacuation radius however, there is a $1.7 \%$ chance that three bridges could be simultaneously impacted. It should be stressed that if the overall size of the AVF were reduced to include a more restricted (less conservative) ellipse around the existing volcanic cones (Figure 1), the probability of each event described above would be dramatically increased.

\section{Micro-scale evacuation vulnerability}

Diurnal changes in population evacuation demand are reflected in the calculated P/EC ratio values (population/ exit capacity, described above). Although no data exists for threshold P/EC ratios for different roads in Auckland, a comparison of values provides a first-hand relative assessment of potential congestion areas. There is a high concentration of areas with elevated $\mathrm{P} / \mathrm{EC}$ ratios during the day in and around the CBD, which at night is dramatically reduced. The reverse is true for many outlying suburbs, particularly those in West Auckland and the North Shore, which experience much higher ratios at night. This makes intuitive sense as many people 


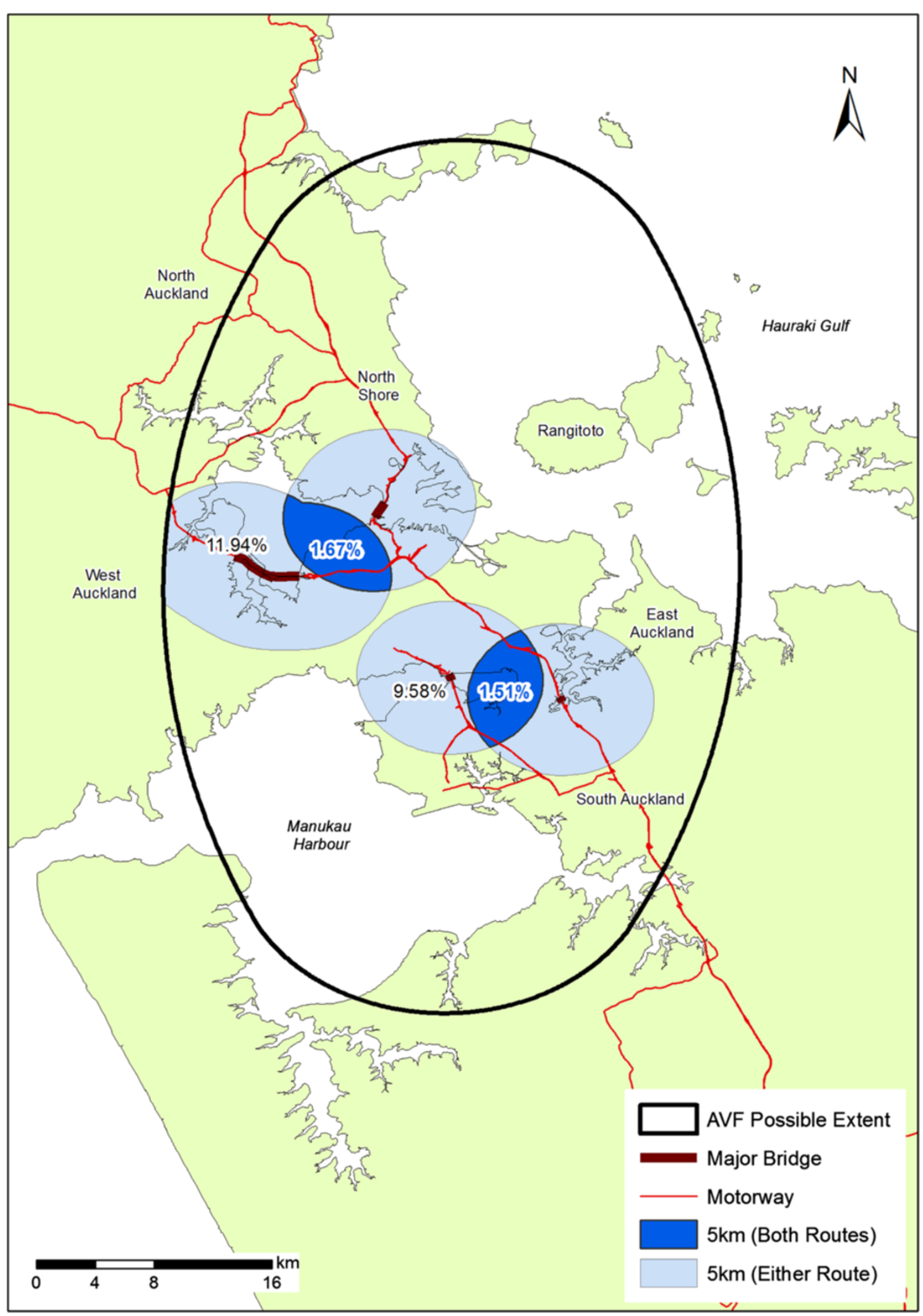

Figure 5 Directional bridge vulnerability for a $\mathbf{5}$ kilometre evacuation radius. This shows the probabilities of either bridges and both bridges to the north or south being impacted by an eruption. Note that if a smaller, less-conservative ellipse representing the extent of the AVF were used in this study, the probability of each event would be higher. 
travel from the suburbs to the CBD for work each day. Table 4 lists the five neighbourhoods with the highest and five neighbourhoods with the lowest P/EC ratios. Two of the five neighbourhoods with the greatest net population gain during the day, the CBD and Auckland Airport, also have the two highest $\mathrm{P} / \mathrm{EC}$ ratios during the day $(1,819$ and 1,574 people per exit lane, respectively). Night-time P/EC ratios for many of these neighbourhoods are significantly lower. Neighbourhoods with the greatest net population losses during the day also have some of the highest night-time P/EC ratios. Overall, the highest $\mathrm{P} / \mathrm{EC}$ ratios during the night are far lower than the highest $\mathrm{P} / \mathrm{EC}$ ratios during the day. Only two neighbourhoods, both in south Auckland, have P/EC ratios over 1,000 at night.

When graphically comparing daytime and night-time $\mathrm{P} / \mathrm{EC}$ ratios, the prevalence of neighbourhoods with lower P/EC ratios is very clear. Based on the Brisbane Strategic Transport Model (Brisbane City Council 2007) access roads, such as those connecting neighbourhoods to primary roads, can facilitate the movement of up to 600 vehicles per hour. Therefore $\mathrm{P} / \mathrm{EC}$ ratios $>600$ are very likely to cause congestion and the value was used as a benchmark. In our study, the number of neighbourhoods with $\mathrm{P} / \mathrm{EC}$ values greater than 600 is very small both at day and night (Figure 6).

Geographic features are of great consequence when assessing P/EC ratios. Neighbourhoods with both motorway and water boundaries have higher P/EC ratios. This is to be expected, as boundaries work as constraining geographic features limiting the number of exits. The results of statistical analysis of neighbourhood boundaries are shown in Table 5. All p-values, with two exceptions, were less than 0.05 and thus statistically significant.

These results show that there is a significant difference between neighbourhoods with only motorways as boundaries and neighbourhoods with neither water nor motorways as boundaries during the day (i.e. when people are at work). However, at night there is no statistically significant difference. Contrastingly, neighbourhoods with only water boundaries are significantly different during the night (i.e. when those people return home), but not during the day. This is likely due to more residential neighbourhoods being located close to water features which provide both aesthetic and recreational value. Neighbourhoods containing businesses are more likely to occur close to motorway on- and off-ramps, which enable easy access for workers and goods. Therefore, when either of these neighbourhood types reach their peak population, they usually become more difficult to evacuate.

The numeric results of the HH/EC ratio and Car/EC ratio calculations are presented in Table 6. Results of both studies were found to be similar to those of the night-time $\mathrm{P} / \mathrm{EC}$ ratios. $\mathrm{HH} / \mathrm{EC}$ ratios were generally one third that of the P/EC ratios; this correlates with the fact that the mean Auckland household has three residents (Statistics New Zealand 2006). Car/EC ratios were around half as large as $\mathrm{P} / \mathrm{EC}$ ratios, which correlates with there being roughly twice as many people as cars in Auckland (Statistics New Zealand 2006, New Zealand Transport Agency 2009). The minima Car/EC ratios at or bordering zero are suspect and likely due to the fact that such areas have very low residential populations. When compared to P/EC ratios and Car/EC ratios, $\mathrm{HH} /$ $\mathrm{EC}$ ratios represent the best-case scenario, as they minimise the overall number of evacuating units and thus the ratio, thereby producing fewer units per exit lane.

\section{Macro-scale evacuation vulnerability}

For inter- and intra-regional evacuations, flows often exceeded 50,000 vehicles along motorway sections, but

Table 4 Neighbourhoods with highest and lowest Population/Evacuation Capacity (P/EC) ratios for day and night

\begin{tabular}{|c|c|c|c|c|c|c|c|}
\hline \multicolumn{4}{|c|}{$D A Y^{*}$} & \multicolumn{4}{|c|}{$\mathrm{NIGHT}^{*}$} \\
\hline Rank & Neighbourhood & P/EC Day & P/EC Night & Rank & Neighbourhood & P/EC Night & P/EC Day \\
\hline 1 & Puhoi & 10.3 & 28.5 & 1 & Druces West & 4.3 & 710.9 \\
\hline 2 & Gardens East & 11.3 & 42.9 & 2 & Manukau South & 6.5 & 361.3 \\
\hline 3 & Glenbrook & 15.1 & 34.6 & 3 & Sylvia Park & 10.3 & 1292.4 \\
\hline 4 & Ormiston North & 18.9 & 41.9 & 4 & Hampton Park & 10.8 & 595.1 \\
\hline 5 & Greenhithe & 23.6 & 84.2 & 5 & Pukekohe North & 16.2 & 123.9 \\
\hline 234 & Sylvia Park & 1292.4 & 10.3 & 234 & Wattle Farm & 778.6 & 450.0 \\
\hline 235 & Rosedale & 1362.5 & 267.0 & 235 & Sunnynook & 842.1 & 376.3 \\
\hline 236 & Hingaia & 1567.9 & 685.3 & 236 & Gulf Harbour & 886.0 & 448.3 \\
\hline 237 & Akld Airport & 1574.3 & 89.9 & 237 & E Howick Beaches & 1000.6 & 653.8 \\
\hline 238 & Akld CBD & 1818.9 & 447.0 & 238 & Mt. Mangere & 1291.4 & 753.4 \\
\hline
\end{tabular}

*The highest and lowest ranked P/EC ratios are shown in bold font. These are compared with the corresponding P/EC ratios for the contrasting diurnal time shown in normal font. For location of neighbourhoods please visit: http://www.stats.govt.nz/StatsMaps/Home.aspx. 


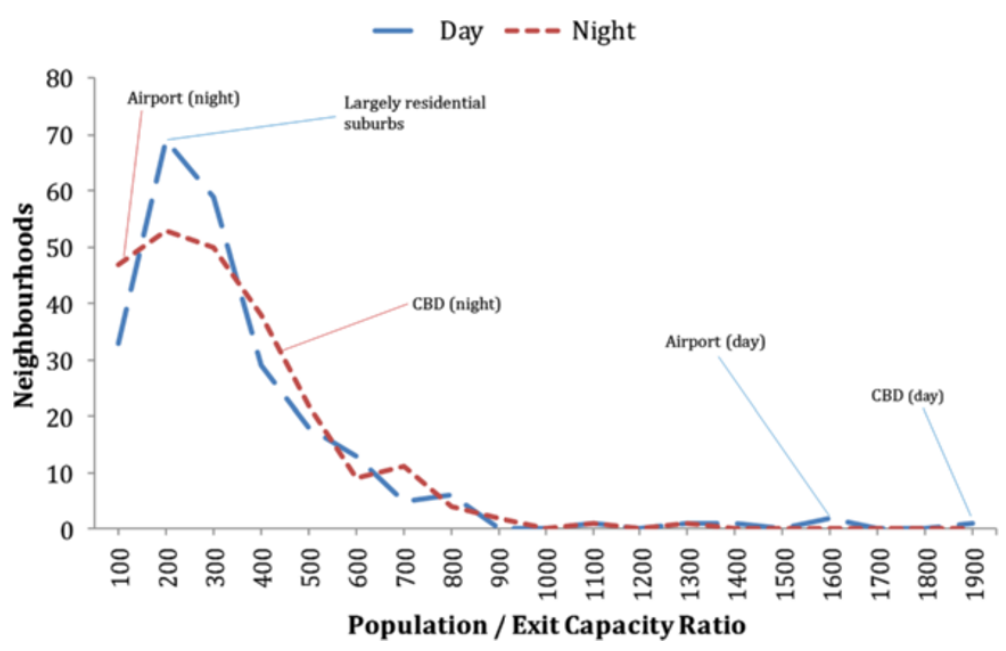

Figure 6 Daytime and night-time Population/Exit Capacity (P/EC) ratios. The P/EC ratios for key neighbourhoods described in the text are shown on the graph.

rarely exceeded 20,000 vehicles for arterial and major roads. Symbolising flows along different routes by means of varying line thickness allows these differences in flows to be visualised (Figure 7).

In scenarios run for Auckland, the maximum VOC ratio for inter-regional evacuation was 92, which was established for a daytime evacuation with multiple vehicles, based on the maxima vent location and a large shadow evacuation. This suggests that the volume of traffic greatly exceeded the lane's capacity. VOC ratios were highest along motorways and in inter-regional evacuation models. In such cases, speeds were reduced to miniscule fractions of a $\mathrm{km} \mathrm{h}^{-1}$, i.e. traffic had come to a virtual standstill. The maximum VOC ratios for intra-regional evacuations however, were much lower (maximum $=6.56$ ), a trend which was also depicted in the total network travel times (i.e. the cumulative time for all drivers to reach their final destinations). For the inter-regional evacuations modelled, clearance time was found to be in the order of days to years. Intra-regional evacuation clearance times were found to be much lower, ranging from one to nine hours. This was regardless of the level of network detail or number of connectors employed.

Table 5 Statistical t-test comparison of neighbourhood boundary types

\begin{tabular}{llll}
\hline $\boldsymbol{\mu}_{\mathbf{1}}$ & $\boldsymbol{\mu}_{\mathbf{2}}$ & $\mathbf{p}$-value (day) & $\mathbf{p}$-value (night) \\
\hline Both & Neither & 0.020 & 0.012 \\
Motorway Only & Neither & 0.020 & 0.632 \\
Water Only & Neither & 0.623 & 0.004 \\
Neither & All & 0.020 & 0.034 \\
\hline
\end{tabular}

\section{Discussion}

Impact of diurnal population shifts on evacuation demand

Neighbourhoods with large daily population influxes are likely to be more difficult to evacuate during the day than at night because a greater demand will be placed on a static infrastructure network. Neighbourhoods with net losses will become easier to evacuate during the day (Tomsen 2010). A key finding of the population evacuation demand results is that demand values are high around the CBD during the day but become more widely dispersed at night. This can be attributed to a diurnal population shift, which is likely due to commuters moving away from the CBD toward peripheral, residential areas during the evening.

Night-time evacuation demand figures are significantly lower for the low-mobility population than the general population. In terms of geographic distribution, the North Shore has much less of a low-mobility evacuation demand as residents living there have greater access to motor vehicles. The reverse is true for South Auckland, which, when utilising the smaller two evacuation radii, nearly rivals the $\mathrm{CBD}$ as the peak evacuation demand centre. Daly et al. (2007) estimated that the maximum combined capacity of the Auckland public transportation system for an initial outward movement, assuming all public resources could be mustered, was just under 50,000 passenger seats. This capacity is more than sufficient for all night-time low-mobility evacuation models in our study, but not the 5 kilometre and 8 kilometre daytime low-mobility evacuation models. With a 5 kilometre evacuation radius, there is roughly a $2 \%$ chance this capacity will be exceeded during a daytime evacuation. This probability grows to roughly $35 \%$ with an 8 kilometre evacuation radius. Similar issues associated 
Table 6 Neighbourhoods with highest and lowest Household/EC Ratios and Car/EC Ratios

\begin{tabular}{|c|c|c|c|c|c|c|c|c|c|}
\hline \multicolumn{5}{|c|}{ Household/Evacuation Capacity (HH/EC)* } & \multicolumn{5}{|c|}{ Car/Evacuation Capacity (Car/EC)* } \\
\hline Rank & Neighbourhood & $\mathrm{HH} / \mathrm{EC}$ & Car/EC & P/EC Night & Rank & Neighbourhood & Car/EC & $\mathrm{HH} / \mathrm{EC}$ & P/EC Night \\
\hline 1 & Manukau South & 0.5 & 0.7 & 6.5 & 1 & Druces West & 0.0 & 2.1 & 4.3 \\
\hline 2 & Druces West & 2.1 & 0.0 & 4.3 & 2 & Sylvia Park & 0.0 & 3.2 & 10.3 \\
\hline 3 & Sylvia Park & 3.2 & 0.0 & 10.3 & 3 & Manukau South & 0.7 & 0.5 & 6.5 \\
\hline 4 & Hampton Park & 4.9 & 6.2 & 10.8 & 4 & Pukekohe North & 5.5 & 5.3 & 16.2 \\
\hline 5 & Hobsonville & 5.2 & 9.6 & 16.7 & 5 & Hampton Park & 6.2 & 4.9 & 10.8 \\
\hline 234 & West Tamaki & 246.4 & 361.4 & 771.5 & 234 & Hingaia & 454.5 & 229.0 & 685.3 \\
\hline 235 & Sunnynook & 280.1 & 472.9 & 842.1 & 235 & Sunnynook & 472.9 & 280.1 & 842.1 \\
\hline 236 & Gulf Harbour & 313.1 & 540.0 & 886.0 & 236 & Gulf Harbour & 540.0 & 313.1 & 886.0 \\
\hline 237 & E Howick Beaches & 328.2 & 628.1 & 1000.6 & 237 & E Howick Beaches & 628.1 & 328.2 & 1000.6 \\
\hline 238 & Mt. Mangere & 411.6 & 643.2 & 1291.4 & 238 & Mt. Mangere & 643.2 & 411.6 & 1291.4 \\
\hline
\end{tabular}

*The highest and lowest ranked Household/EC ratios and Car/EC ratios are shown in bold font. These are compared with the corresponding Car/EC ratios and Household/EC ratios, and also P/EC ratios, which are shown in normal font. For location of neighbourhoods please

visit: http://www.stats.govt.nz/StatsMaps/Home.aspx.

with evacuating low-mobility populations are frequently encountered worldwide. For example, during Hurricane Katrina, there were some clear failures, particularly when it came to evacuating low-mobility groups in New Orleans (Wolshon 2006).

\section{Bridge vulnerability and importance of maritime transport}

In terms of transportation networks, a worst-case scenario for Auckland is a volcanic eruption impacting both bridges connecting the isthmus in the same direction; a $1.7 \%$ and $1.5 \%$ chance for both north and both south bridges respectively, for a 5 kilometre evacuation radius. Such an event would virtually sever all motor vehicle movement into and out of Auckland in that direction. Values for public transport network accessibility for the population with no access to a private vehicle were always greater than night-time values for the entire population. This makes intuitive sense, as people without a vehicle would likely live closer to public transportation assets to fulfil any day-to-day transportation requirements. It should be noted that while motorways and public transit routes are likely to become jammed, not helped by the constraining geography in Auckland, the likelihood of such congestion on the waters of the Waitemata and Manukau Harbours is low. Boats, unlike most cars and buses, are capable of transporting extensive cargo and are often kept stocked with essential survival materials including food, water and clothes. Therefore, although non-traditional, a part-maritime based evacuation may hold several advantages in Auckland. In 2008, such an evacuation was successfully demonstrated in Chaitén, Chile where over 5,000 people were evacuated by boat shortly before the town was inundated by lahars originating from the nearby volcano (Major and Lara 2013, Wilson et al. 2009). Marinas and ferry terminals are more limited in numbers than boat ramps in Auckland and the accessibility figures reflect this. Boat ramps however, have the major disadvantage of additional preparation time required as many boat owners would initially have to return home from work during the day to collect boats for an evacuation, perhaps via congested roads. Despite this, the potential for maritime evacuation by private boats and ferries should not be underestimated in Auckland.

\section{Relative evacuation difficulty as revealed by $\mathrm{P} / \mathrm{EC}$ ratios}

Micro-scale vulnerability analysis using $\mathrm{P} / \mathrm{EC}$ ratios can be produced anywhere that population and road network data are available. In this study, such ratios were found to be effective in determining which areas, due to their infrastructure design, pose greater difficulties for evacuation. A comparison of daytime and night-time P/ EC ratios (Figure 6) shows that the number of neighbourhoods with relatively large $\mathrm{P} / \mathrm{EC}$ ratios is low. However, these neighbourhoods are of greatest concern as they will likely be more difficult to evacuate on a micro-scale. Two of the five neighbourhoods with the greatest net population gain during the day, the CBD and Auckland Airport, also have the two highest P/EC ratios during the day. This indicates that neighbourhoods experiencing the largest daytime population influx are some of the most difficult to evacuate during the day because of the inflexible infrastructure setup. A similar trend is observed for neighbourhoods with high nighttime population influx. Neighbourhoods such as Wattle Farm in South Auckland and Eastern Howick Beaches in East Auckland (Figure 1), with the greatest net population losses during the day, also have some of the highest night-time $\mathrm{P} / \mathrm{EC}$ ratios. This is most likely attributed to the return of school children and workers during evening hours. This suggests that residential neighbourhoods 

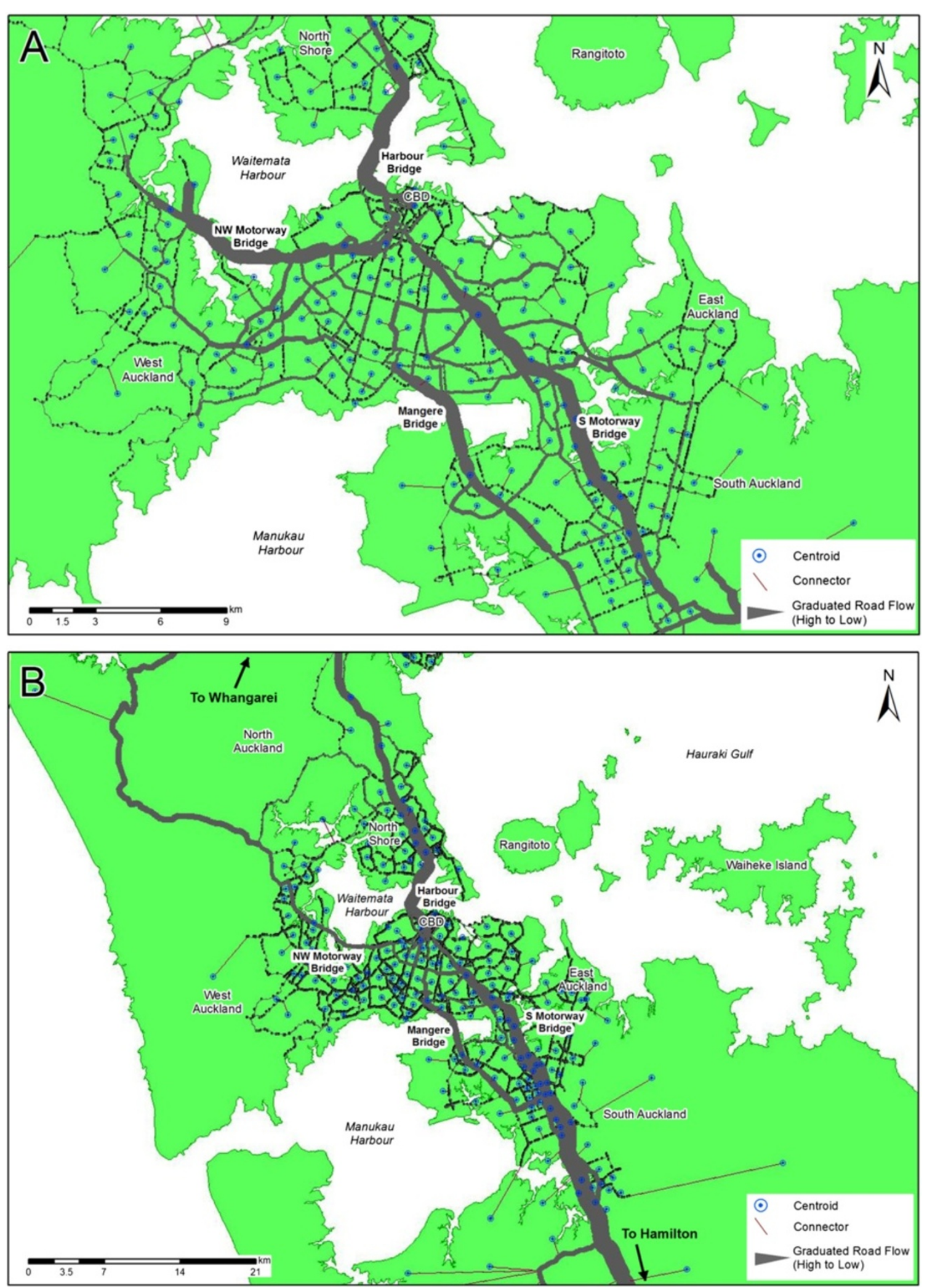

Figure 7 Symbolised graduated road flows for intra-regional (A) and inter-regional (B) evacuation. The total flows over the entire network equals the total number of vehicles involved in the evacuation. Along motorway sections, flows often exceed 50,000 vehicles. Flows for other arterial and major roads rarely exceeded 20,000 vehicles. 
that experience the greatest net population influxes at night are also some of the most difficult to evacuate at night as a result of infrastructure setup. Overall, however, the highest P/EC ratios during the day are far higher than the highest P/EC ratios during the night. This indicates that evacuations in the top-five most challenging neighbourhoods are much more challenging during the day than at night. This can be attributed to the larger number of residential neighbourhoods than business and industrial neighbourhoods in Auckland. This reflects a metropolitan standard; in order to support an urban core, multiple feeder (i.e. residential) neighbourhoods are required.

Vulnerability trends related to boundary types also emerged during the study. Significantly higher P/EC ratios were experienced by neighbourhoods with both water and motorway boundaries than neighbourhoods with neither. Contrasting $\mathrm{P} / \mathrm{EC}$ ratios observed for neighbourhoods with the different boundary types (i.e. high $\mathrm{P} / \mathrm{EC}$ ratios for those with motorways and low $\mathrm{P} /$ EC ratios for those with water during the day) are likely attributable to the neighbourhood type. Business and industrial neighbourhoods are more likely to be located near motorways to enable easy access for workers and goods. Residential neighbourhoods, in contrast, are more likely to be located close to water features as they provide aesthetic and recreational value. Motorways offer neither of these. The minima Car/EC ratios at or bordering zero for some neighbourhoods may be due to the fact that some areas, such as Druces West and Sylvia Park (both in South Auckland), have virtually no residential population and are primarily used for business purposes. Such areas will likely be easy to evacuate at night but will be difficult to evacuate during business hours when there are high populations and limited capacities.

\section{Intra-regional vs. inter-regional evacuation}

The preference for Auckland Civil Defence and Emergency Management is to localise evacuations as much as possible, moving evacuees outside the danger zone (via a welfare facility for registration purposes) but keeping them close to home and within the region (MCDEM 2008). There were 151 Civil Defence and Emergency Management designated welfare facilities at the time of this study, including schools, churches and sports stadiums. More than half of Auckland's population were located within 5 minutes driving distance of the nearest facility and virtually all Aucklanders can access one within a 15-minute drive. However, the nearest welfare facility will not always be available or suitable for evacuation purposes (for example it might lie in the evacuation zone or be impacted by localised critical infrastructure disruption). In such cases it will be necessary for evacuees to travel greater distances until they reach an alternative welfare facility in a safe location before heading to their final destination, wherever that may be. During a large phreatomagmatic eruption, critical infrastructure across Auckland may be crippled and an inter-regional evacuation may be necessary. Prior to this study, the best estimate of an evacuation clearance time for Auckland was developed during Exercise Ruaumoko in 2008. During this exercise, civil defence authorities allowed less than 24 hours in order to evacuate a 5 kilometre radius zone (Horrocks 2008a). However, this clearance time was only postulation and lacked any scientific backing. Though a conclusive figure will be unavailable until an actual evacuation is conducted, the next best solution, deriving scientifically backed estimates by means of evacuation modelling, was undertaken in this study.

Marco-scale evacuation vulnerability analysis showed that clearance time for inter-regional evacuation was in the order of days to years. This indicates that congestion is not limited to specific links, but rather endemic in the network due to limited capacities and excessive demand. Evacuees would most likely walk rather than wait in traffic congestion for such prolonged periods and the capabilities of the TransCAD model can therefore be deemed somewhat limited for computing movement times over such large distances especially with heavy congestion. In essence however, it can be concluded that the Auckland road network is ill suited for large-scale egress movements at present. Despite this, one major trend was identified from the inter-regional modelling: as more detail is added to the road network, thus allowing evacuees more route choice flexibility, clearance times are reduced. In the future it would be worthwhile recalculating macro-scale evacuation vulnerability using an evacuation modelling program specifically designed to accommodate high congestion levels, which could also be used to validate intra-regional evacuation results.

The relatively short clearance times for intra-regional evacuations mean that there is considerable merit to intra-regional over inter-regional evacuation from a mobility standpoint. The reasons for lower intra-regional clearance times are heavily associated with path lengths. While inter-regional evacuees commonly traversed roughly 150 kilometres of road network, intra-regional evacuees seldom travelled further than 10 kilometres. Network capacity is another contributing factor. VOC analysis confirmed that motorways would be congested in all evacuation scenarios, regardless of the amount of network detail. Yet, intra-regional evacuations are less dependent on the motorway network than inter-regional evacuations, as there are more alternate routes due to dense urban development in the city. It should be noted that all of the clearance time figures represent the 
movement times once evacuees have reached the Traffic Analysis Zone boundary and do not include preparation times (estimated to be 1 to 2 days in Auckland (Auckland CDEM Group 2008b)) or intra-zonal movement times.

\section{Conclusions}

This study has numerically demonstrated a future eruption in the AVF will almost certainly create considerable evacuation demands, which require considerable planning. Although the locations of new eruptions are unknown, adopting a non-specific eruption vent approach has allowed the impacts at all locations, and population and infrastructure vulnerability to be modelled and assessed. Our key conclusions and recommendations are:

- Eruptions in the central Auckland isthmus area are likely to generate high evacuation demand, peaking at just over half a million evacuees in places. This is particularly relevant given that rapid evacuation is likely to be needed, i.e. within 48 hours. High P/EC ratios in the same regions indicate that transportation infrastructure may struggle to cope. Based on a 5 kilometre evacuation radius, there is just a $4 \%$ chance that an eruption would generate no evacuation demand.

- Daytime eruptions near Auckland Airport and in business districts, particularly the CBD, will generate high population evacuation demand. Daytime maximum population evacuation demand figures are around three times higher than night-time eruptions in these areas due to the large population influx from residential suburbs during the day. There is also a substantial low-mobility population in the central Auckland area during the day, largely attributable to the number of students. Indeed the predicted daytime maximum low-mobility evacuation demand may be more than twice the seating capacity of Auckland's total public transportation assets meaning that return trips may be required to accommodate such demand. Large daytime increases in population evacuation demand combined with high P/EC ratios may favour an evacuation at night in some areas (such as the CBD) to avoid severe congestion (although this needs to be counterbalanced by the limited visibility and other constraints of evacuation by night). Delaying the call to evacuate until the majority of people are home, or advising people to remain at home to await an evacuation decision, should be considered. This supports the consideration in the current mass evacuation plan for Auckland which favours evacuation from home due to likely reduced preparation time (Auckland CDEM Group 2008b).
- The bus network is accessible by foot to nearly the entire Auckland population but, as with private transport, is subject to road congestion that commonly plagues evacuations. There is a moderate chance (13-39\% depending on the eruptive magnitude) that one of the four motorway bridges would be impacted and an up to $8 \%$ chance that multiple bridges facilitating evacuation in the same direction are impacted. Any impacts to bridges will likely increase congestion and further disrupt evacuation. Transportation by boat and rail is significantly less accessible but these modes rarely experience major congestion in Auckland. For this reason, the value of maritime evacuation by ferries, and private boats using boat ramps and marinas, should not be underestimated. This could be particularly beneficial in neighbourhoods with high population/exit capacity that have both water and motorway boundaries. Maritime evacuation would play to Auckland's geographic strength: its double harbour access, and would likely ease congestion on available motorways. In addition, the Ports of Auckland east coast seaport (adjacent to the CBD) provides an opportunity for people to be evacuated by a non-traditional mode of maritime transport, namely cargo vessels.

- Each of the modelled TransCAD scenarios experienced massive congestion, as thousands of evacuees flooded a limited number of evacuation routes. Congestion was not limited to specific links, but rather endemic in the network due to limited capacities and excessive demand. Intra-regional, rather than inter-regional, evacuations were favoured, reducing total network clearance times by multiple orders of magnitude (from days to between one and nine hours). This suggests that evacuation to destinations within the Auckland region should be given preference over evacuation to destinations outside the region if possible.

- TransCAD results also suggest that route choice flexibility will likely reduce the clearance time for evacuation. Such choices may be critical for interregional evacuations to be completed within manageable timeframes. However for this to work, evacuees must either have prior knowledge of the various network connections or be informed of them using signage and/or other communication methods.

- The survivability of Auckland's critical infrastructure during volcanic activity is an important unknown. Functional transportation networks are fundamental for evacuation purposes. Whether infrastructure assets, including bridges, tunnels, traffic lights, signs and motorways will be functional following volcanic activity such as tremors and ash fall determines 
which routes are available to evacuees and radically impacts egress movements. Further study is required in this field.

\section{Abbreviations}

AVF: Auckland Volcanic Field; P/EC: Population to exit capacity; $\mathrm{HH}$ / EC: Household to exit capacity; nHH: Number of households; Car/EC: Car to exit capacity; TAZ: Traffic Analysis Zone; CBD: Central Business District; VOC: Volume-Over-Capacity.

\section{Competing interests}

The authors declare that they have no competing interests.

\section{Authors' contribution}

Supported by the expertise and direction of JML and MG, ET acquired data, planned and conducted the research and undertook all statistical analysis for the study. TMW contributed knowledge and skills, particularly regarding the modelling component of the work and DMB participated through the writing and editing of this manuscript. All authors have read, reviewed and approved the final manuscript.

\section{Acknowledgements}

We are grateful to the Rotary Foundation for providing funding for ET to conduct the research. We thank Statistics New Zealand, the Ministry of Education and the former Auckland Regional Council for the supply of data. We also thank Associate Professor André Dantas, in Civil Engineering at the University of Canterbury at the time of the research, for his support with the TransCAD studies. JML gratefully acknowledges support from the New Zealand Earthquake Commission.

\section{Author details}

${ }^{1}$ School of Environment, The University of Auckland, Private Bag 92019 Auckland, New Zealand. ${ }^{2}$ Centre for eResearch \& Department of Computer Science, University of Auckland, Private Bag 92019, Auckland, New Zealand. ${ }^{3}$ Centre for Risk, Resilience and Renewal, Department of Geological Sciences, University of Canterbury, Private Bag 4800, Christchurch, New Zealand. ${ }^{4}$ Present address: CMR 464, Box 2361, APO, AE 09226, USA.

Received: 16 August 2013 Revised: 27 November 2013 Accepted: 14 February 2014

Published: 31 Mar 2014

\section{References}

Allen SR, Smith IEM (1994) Eruption styles and volcanic hazard in the Auckland Volcanic Field, New Zealand. Geoscience Reports of Shizuoka University 20:5-14

ArcGIS (2009) GIS software: version 9.3.1. Environmental Systems Research Institute (ESRI), Redlands, California

Auckland CDEM (2013) Auckland Volcanic Field contingency plan., Available from: http://www.aucklandcivildefence.org.nz/About-Us/Document-Library/ Supporting-Plans/. Accessed 22 June 2013

Auckland CDEM Group (2008a) Final exercise report: exercise Ruaumoko '08. Auckland Regional Council, Auckland, New Zealand

Auckland CDEM Group (2008b) Mass evacuation plan: group functional plan P2. Auckland Regional Council, Auckland, New Zealand

Auckland Regional Council (2009a) Monitor Auckland: tracking our progress. Auckland Regional Council, Auckland, New Zealand

Auckland Regional Council (2009b) Trends and issues (transport challenges): regional land transport strategy working report. Auckland Regional Council, Auckland, New Zealand

Baker EJ (1991) Hurricane evacuation behavior. International Journal of Mass Emergencies and Disasters 9:287-310

Bascetta C (2006) Disaster preparedness preliminary observations on the education of vulnerable populations due to hurricanes and other disasters testimony. In: United States Government Accountability Office (ed) Testimony before the special committee on aging. U.S. Senate, Washington D.C

Bebbington MS, Cronin SJ (2011) Spatio-temporal hazard estimation in the Auckland volcanic field, New Zealand, with a new event-order model. Bull Volcanol 73(1):55-72
Beca Carter Hollings and Ferner Ltd (2002) Contingency plan for the Auckland Volcanic Field. , Auckland, New Zealand, http://www.arc.govt.nz/albany/fms/ main/Documents/Council/Civil\%20defence\%20emergency\%20management/ Publications\%20\&\%20factsheets/Auckland\%20Volcanic\%20Plan\%20(VCP).pdf. Accessed 16 June 2013

Belousov A, Voight B, Belousova M (2007) Directed blasts and blast-generated pyroclastic density currents: a comparison of the Bezymianny 1956, Mount St Helens 1980, and Soufrière Hills, Montserrat 1997 eruptions and deposits. Bull Volcanol 69(7):701-740, 10.1007/s00445-006-0109-y

Blake S, Smith I, Wilson C, Leonard G (2006) Lead times and precursors of eruptions in the Auckland Volcanic Field, New Zealand: indications from historical analogues and theoretical modelling. Consultancy Report 2006/34, GNS Science, Lower Hutt, New Zealand

Brisbane City Council (2007) Brisbane Strategic Transport Model (BSTM) version 6.0. Brisbane City Council, Brisbane, Australia

Browne FL (1958) Theories of the combustion of wood and its control: a survey of the literature. Forest Products Laboratory, U.S, Forest Service Research Legacy, Report 2136

Chakraborty J, Tobin GA, Montz BE (2005) Population evacuation: assessing spatial variability in geophysical risk and social vulnerability to natural hazards. Natural Hazards Review 6:23-33

Church RL, Cova TJ (2000) Mapping evacuation risk on transportation networks using a spatial optimization model. Transportation Research Part C: Emerging Technologies 8:321-336

Cola RM (1996) Responses of Pampanga households to lahar warnings: lessons from two villages in the Pasig-Patrero River watershed. In: Newhall CG, Punongbayan RS (eds) Fire and Mud. Philippine Institute of Volcanology and Seismology and University of Washington Press, Quezon City and Seattle

Cole J, Blumenthal E (2004) Evacuate: what an evacuation order given because of a pending volcanic eruption could mean to residents of the Bay of Plenty. Tephra 21:46-52

Cova TJ (1999) GIS in emergency management. Geographical Information Systems: Principles, Techniques, Applications and Management. John Wiley and Sons, New York

Cova TJ, Church RL (1997) Modelling community evacuation vulnerability using GIS. Int J Geogr Inf Sci 11:763-784

Cutter CL (2003) Gl science, disasters, and emergency management. Trans GIS 7:439-446

Daly M, Hoskin K, Leonard G (2007) Physical evacuation workshop, 2007 (facilitator comments). Auckland Regional Council, Auckland, New Zealand

Dosa DM, Grossman N, Wetle T, Mor V (2007) To evacuate or not to evacuate: lessons learned from Louisianna nursing home administrators following Hurricanes Katrina and Rita. Journal of the American Medical Directors Association 8:142-149

Dow K, Cutter SL (2002) Emerging hurricane evacuation issues: Hurricane Floyd and South Carolina. Natural Hazards Review 3:267-285

Drabek TE (1986) Human system responses to disaster. Springer, New York

Franzese O, Liu C (2008) Emergency evacuations, transportation networks. In: Shekhar S, Xiong H (eds) Encyclopaedia of GIS. Springer, New York

Horrocks J (2008a) Evacuation progression script summary, Exercise Ruaumoko 2008. Ministry of Civil Defence and Emergency Management, New Zealand

Horrocks J (2008b) Learning from Exercise Ruaumoko, Exercise Ruaumoko 2008. Ministry of Civil Defence and Emergency Management, New Zealand

Hushon J, Kelly RB, Rubin C (1989) Identification and analysis of factors affecting emergency evacuations. Nuclear Management and Resources Council Inc. (NUMARC), Washington D.C

Ketteridge AM, Clarke L, Fordham M (1996) EUROflood: evacuation 1996, technical annex 14 for the evacuation module. Flood Hazard Research Centre, University of Middlesex, Enfield, United Kingdom

Klepeis NE, Nelson WC, Ott WR, Robinson JP, Tsang AM, Switzer P, Behar JV, Hern SC, Engelmann WH (2001) The National Human Activity Pattern Survey (NHAPS): a resource for assessing exposure to environmental pollutants. J Expo Anal Environ Epidemiol 11:231-252

Le Corvec N, Bebbington MS, Lindsay JM, McGee LE (2013a) Age, distance and geochemical evolution within a monogenetic volcanic field: analyzing patterns in the Auckland Volcanic Field eruption sequence. Geochemistry, Geophysics, Geosystems 14(9):3648-3665

Le Corvec N, Spörli KB, Rowland J, Lindsay J (2013b) Spatial distribution and alignments of volcanic centers: clues to the formation of monogenetic volcanic fields. Earth Sci Rev 124:96-114

Leonard R (1985) Mass evacuation is disasters. J Emerg Med 2:279-286 
Lindell MK, Perry RW (1992) Behavioral foundations of community emergency planning. Hemisphere Publishing, Washington D.C

Lindell MK, Prater CS (2006) Evacuation from Hurricane Katrina: Jefforson and St. Charles parishes. National Hurricane Conference, Orlando, Florida

Lindell MK, Prater CS (2007) Critical behavioural assumptions in evacuation time estimate analysis for private vehicles: examples from hurricane research and planning. Journal of Urban Planning and Development 133:18-29

Lindell MK, Lu J-C, Prater CS (2005) Household decision making and evacuation in response to Hurricane Lili. Natural Hazards Review 6:171-179

Lindsay JM (2010) Volcanoes in the big smoke: a review of hazard and risk in the Auckland Volcanic Field. Institute of Earth Science and Engineering and School of Environment. University of Auckland, Auckland, New Zealand

Lindsay JM, Marzocchi W, Jolly G, Constantinescu R, Selva J, Sandri L (2010) Towards real-time eruption forecasting in the Auckland volcanic field: application of BET_EF during the New Zealand national disaster Exercise 'Ruaumoko'. Bull Volcanol 72:185-204

Lindsay JM, Leonard GS, Smid ER, Hayward BW (2011) Age of the Auckland Volcanic Field: a review of existing data. N Z J Geol Geophys 54(4):379-401

Major JJ, Lara LE (2013) Overview of Chaitén volcano. Andean Geology 40(2):196-215

Marrero JM, Garcia A, Llinares A, Rodriguez-Losada JA, Ortiz R (2010) The Variable Scale Evacuation Model (VSEM): a new tool for simulating massive evacuation processes during volcanic crises. Natural Hazards and Earth Systems Sciences 10:747-760

Marzocchi W, Woo G (2007) Probabilistic eruption forecasting and the call for an evacuation. Geophysical Research Letters 34:1-4

MCDEM (2008) Mass evacuation planning: director's guidelines for civil defence emergency management (CDEM) groups, DGL 07/08. Ministry of Civil Defence and Emergency Management., http://www.civildefence.govt.nz/ memwebsite.nsf/Files/Director_Guidelines/\$file/Mass-evacu-planningDGL0708.pdf. Accessed 12 May 2013

Mileti DS, Bolton PA, Fernandez G, Updike RG (1991) The eruption of Nevado Del Ruiz volcano Colombia, South America, November 13, 1985. Commission on Engineering and Technical Systems (National Academy Press), Washington, D.C

Moriarty K, Ni D, Collura J (2007) Modelling traffic flow under emergency evacuation situations: current practices and future directions. 86th Transportation Research Board Annual Meeting. Transportation Research Board, Washington, D.C

Morrow BH (1999) Identifying and mapping community vulnerability. Disasters 23:1-18

Needham AJ, Lindsay JM, Smith IEM, Augustinus P, Shane PA (2011) Sequential eruption of alkaline and sub-alkaline magmas from a small monogenetic volcano in the Auckland Volcanic Field, New Zealand. J Volcanol Geotherm Res 201:126-142

New Zealand Transport Agency (2009) Motor vehicle registration statistics 2008. MVR Statistics, Wellington, New Zealand

NZ Open GPS Maps (2009) Improved NZ road centrelines. Koordinates, https:// koordinates.com/layer/183-improved-nz-road-centrelines-august-2011/ Accessed 10 November 2009

Perry RW, Lindell MK (2003) Preparedness for emergency response: guidelines for the emergency planning process. Disasters 27(4):336-350

Prater C, Wenger D, Grady K (2000) Hurricane Bret post storm assessment: a review of the utilisation of hurricane evacuation studies and information dissemination. College Station, TX, Hazard Reduction and Recovery Centre, A\&M University, Texas

Quarantelli EL (1980) Evacuation behaviour and problems: findings and implications from the research literature. Ohio State University Disaster Research Centre, Columbus, Ohio

Quarantelli EL (1985) Social support systems: some behavioural patterns in the context of mass evacuation activities. Disasters and Mental Health: Selected Contemporary Perspectives 178:122-136

Sandri L, Jolly G, Lindsay J, Howe T, Marzocchi W (2012) Combining probabilistic hazard assessment with cost-benefit analysis to support decision making in a volcanic crisis from the Auckland volcanic field, New Zealand. Bull Volcanol 74:705-723

Shaluf IM (2008) Technological disaster stages and management. Disaster Prevention and Management 17:114-126

Shane P, Gehrels M, Zawalna-Geer A, Augustinus P, Lindsay J, Chaillou I (2013) Longevity of a small shield volcano revealed by crypto-tephra studies (Rangitoto volcano, New Zealand): change in eruptive behaviour of a basaltic field. J Volcanol Geotherm Res 257:174-183
Sherburn S, Scott B, Olsen J, Miller C (2007) Monitoring seismic precursors to an eruption from the Auckland Volcanic Field, New Zealand. N Z I Geol Geophys 50:1-11

Shulman HML (2008) Estimating evacuation vulnerability of urban transportation systems using GIS. Department of Geography, Queen's University, Kingston, Canada

Sparks RSJ (2003) Forecasting volcanic eruptions. Earth Planet Sci Lett 210:1-15

Spörli KB, Eastwood VR (1997) Elliptical boundary of an intraplate volcanic field, Auckland, New Zealand. J Volcanol Geotherm Res 79(3-4):169-179

Statistics New Zealand (2006) Census of population and dwellings. Wellington, New Zealand

Statistics New Zealand (2008) Business demographic statistics Table 11: business demography tables. Wellington, New Zealand

Tierney KJ, Lindell MK, Perry RW (2001) Facing the unexpected: disaster preparedness and response in the United States. Joseph Henry, Washington, D.C

Tobin GA, Whiteford LM (2002) Community resilience and volcano hazard: the eruption of Tungurahua and evacuation of the Faldas in Ecuador. Disasters 26(1):28-48

Tomsen E (2010) GIS-based mass evacuation planning for the Auckland volcanic field. Masters Dissertation, School of Environment, University of Auckland, Auckland, New Zealand

U.S. Department of Transportation (2006) Catastrophic hurricane evacuation plan evaluation: a report to congress (in corporation with the U.S. Department of Homeland Security)., http://www.fhwa.dot.gov/reports/hurricanevacuation/ rtc_chep_eval.pdf. Accessed 01 August 2013

Urbanik T (2000) Evacuation time estimates for nuclear power plants. J Hazard Mater 75:165-180

Wilson T, Leonard G, Stewart C, Johnston D (2009) Rhyolitic eruption of Vulcan Chaitén, Chile. HAZM 401 - Geological Uncertainty, University of Canterbury, Christchurch, New Zealand

Wolshon B (2002) Planning for the evacuation of New Orleans. Institute of Transportation Engineers 72(2):44-49

Wolshon B (2006) The aftermath of Katrina. The Bridge, National Academy of Engineering, Washington D.C, 36(1):27-34

Wolshon B (2008) Empirical characterisation of mass evacuation traffic flow. J Transp Res Board 2041:38-48

Wolshon B, Urbina E, Levitan M (2001) National review of hurricane evacuation plans and policies. Louisiana State University Hurricane Centre, Baton Rouge, LA

Woo G, Grossi P (2009) A new era of volcano risk management. Risk Management Solutions Inc, Stanford, CA, https://support.rms.com/ publications/Nolcano_Risk_Management.pdf. Accessed 20 June 2013

\subsection{6/2191-5040-3-6}

Cite this article as: Tomsen et al: Evacuation planning in the Auckland Volcanic Field, New Zealand: a spatio-temporal approach for emergency management and transportation network decisions. Journal of Applied Volcanology 2014, 3:6

\section{Submit your manuscript to a SpringerOpen ${ }^{\circ}$ journal and benefit from:}

- Convenient online submission

- Rigorous peer review

- Immediate publication on acceptance

- Open access: articles freely available online

- High visibility within the field

- Retaining the copyright to your article

Submit your next manuscript at $>$ springeropen.com 